\title{
In-Situ Diagnostics and Degradation Mapping of a Mixed-Mode Accelerated Stress Test for Proton Exchange Membranes
}

\author{
Yeh-Hung Lai* and Gerald W. Fly ${ }^{* *}$ \\ General Motors Company, Pontiac, MI 48340 \\ *Corresponding author. Tel.: 1585953 5523; fax 12488574054. \\ E-mail address: yeh-hung.lai@gm.com \\ ${ }^{* *}$ Currently affiliated with Ohio State University - Center for Automotive Research
}

Key words: polymer electrolyte membrane fuel cell; proton exchange membrane; degradation; durability; in-situ diagnostics; accelerated stress test 


\begin{abstract}
With increasing availability of more durable membrane materials for proton exchange membrane fuel cells, there is a need for a more stressful test that combines chemical and mechanical stressors to enable accelerated screening of promising membrane candidates. Equally important is the need for in-situ diagnostic methods with sufficient spatial resolution that can provide insights into how membranes degrade to facilitate the development of durable fuel cell systems. In this article, we report an accelerated membrane stress test and a degradation diagnostic method that satisfy both needs. By applying high-amplitude cycles of electrical load to a fuel cell fed with low$\mathrm{RH}$ reactant gases, a wide range of mechanical and chemical stressful conditions can be created within the cell which leads to rapid degradation of a mechanically robust lon Power ${ }^{\mathrm{TM}} \mathrm{N} 111-\mathrm{IP}$ membrane. Using an in-situ shorting/crossover diagnostic method on a segmented fuel cell fixture that provides 100 local current measurements, we are able to monitor the progression and map the degradation modes of shorting, thinning, and crossover leak over the entire membrane. Results from this test method have been validated by conventional metrics of fluoride release rates, physical crossover leak rates, pinhole mapping, and cross-sectional measurements.
\end{abstract}




\section{INTRODUCTION}

One of the key challenges facing the commercialization of automotive fuel cells is the development of membrane electrode assemblies (MEAs) that can meet durability targets. In proton exchange membrane (PEM) fuel cells, the PEM serves to conduct protons from the anode electrode to the cathode electrode of the fuel cell while simultaneously insulating electronic current from passing across the membrane and preventing crossover of the reactant gases, $\mathrm{H}_{2}$ and $\mathrm{O}_{2}$. State-of-the-art PEM fuel cells for high power density operation utilize perfluorosulfonic acid (PFSA) membranes that are typically no more than $25 \mu \mathrm{m}$ thick. To be viable for automotive applications, these membranes must survive 10 years in a vehicle and 5,500 hours of operation including transient operation with start-stop and freeze-thaw cycles. Fuel cells cannot operate effectively if even small amounts of gas are able to permeate the membrane through microscopic pinholes. Ultimately, fuel cells can fail because such pinholes develop and propagate within the polymer membranes. Fuel cells can also fail if electronic current passes through the membranes and causes the system to short. It is critical that these membranes are sufficiently robust to cracking and shorting over the range of conditions experienced during fuel cell operation. In automotive fuel cell systems, there are three primary root causes of membrane failure: (1) Chemical degradation: polymer decomposition caused by the direct attack on the polymer from radical species generated as byproducts or side reactions of the fuel cell electrochemical reactions; (2) Mechanical degradation: membrane fracture caused by cyclic fatigue stresses imposed on the membrane via humidity and thermal fluctuations in a constrained cell; and (3) Shorting: electronic current passing though the membrane caused by local over compression and creep due to cell over compression or topographical irregularities of the neighboring components such as electrodes and gas diffusion layers (GDL).

Chemical degradation of PFSA membranes can be characterized by membrane thinning and the 
emission of $\mathrm{HF}, \mathrm{CO}_{2}$ and $\mathrm{H}_{2} \mathrm{SO}_{4}$ in the fuel cell exhaust streams. The thinning leads to increased rates of gas crossover and mechanical weakening that ultimately result in cell failure. The rate of chemical degradation can be conveniently monitored in situ by quantifying the fluoride emission using a variety of analytical techniques. Although the degree of chemical degradation can be expressed in terms of total membrane fluoride inventory loss, whether this value can provide a meaningful indication of membrane health highly depends on the uniformity of degradation. Liu et al. reported that the MEA can fail at an inventory loss from a low of about $1 \%$ when degradation is very localized to as high as $50 \%$ under uniform degradation [1]. In general, the rate of chemical degradation of PFSA membranes can be accelerated by high temperature, low relative humidity, low electrochemical load, and high reactant gas pressures [1-4]. To assess PEM's chemical durability, the U.S. Department of Energy (DOE) has recommended the use of open circuit voltage (OCV) hold test [5] at a relatively hot and dry test condition of $90^{\circ} \mathrm{C}$ and $30 \% \mathrm{RH}$. In this test, the health of membranes can be monitored through $\mathrm{F}^{-}$release, $\mathrm{H}_{2}$ crossover, high frequency resistance (HFR), and shorting resistance. A chemically durable membrane should be able to endure more than 500 hours in this test without significant degradation according to the durability metrics and targets.

Mechanical degradation of membranes is driven by the fatigue stresses caused by the hygrothermal expansion and contraction of the constrained membrane. As the membrane is weakened by the fatigue stresses, microscopic cracks initiate and propagate through the thickness of the membrane, resulting in the crossover of reactant gases. Although numerous ex-situ tests and material models have been developed to characterize the membrane's mechanical properties to facilitate material screening and development [6-14], the most relevant mechanical durability test remains the humidity cycling test that was proposed by Gittleman et al. $[15,16]$ and later adapted by the U.S. DOE [5]. Cycling between $0 \%$ and supersaturated conditions at $80^{\circ} \mathrm{C}$ in a nonoperating fuel cell, the test can introduce mechanical degradation mimicking that in an operating 
fuel cell. In this test, the health of the membrane can be monitored through the gas crossover and shorting resistance. A mechanically durable membrane should endure 20,000 humidity cycles without exceeding the crossover criterion established by the U.S. DOE.

Shorting occurs when electrons flow directly from the anode to the cathode instead of through the device being powered. Shorting not only can reduce the performance of fuel cells, but also can lead to local heat generation in the vicinity of the short, causing membrane damage that can ultimately result in gas crossover failure in fuel cells. The diagnostic for shorting can be as straightforward as monitoring the ohmic resistance of the fuel cell. However, early detection of shorts can be difficult because the shorting is often localized and the sensitivity of shorting measurement on the cell level can be greatly diminished even for a severe but localized short. Although the U.S. DOE has not published a recommended membrane shorting test, two shorting tests have recently been proposed in the literature. A shorting resistance test using a nonoperating single fuel cell fixture was used by Mittelsteadt and Liu [17] to measure the specific resistance of the specimen at a voltage of $0.5 \mathrm{~V}$ applied across the cell at $95^{\circ} \mathrm{C}$ and $100 \% \mathrm{RH}$ or under the U.S. DOE humidity cycling test condition with inert nitrogen gas flowing on both sides of the membrane. As the test proceeds, the compression load of the cell is increased stepwise through a pre-determined compression schedule. As opposed to the constant voltage applied to the cell to measure the shorting resistance, an alternate shorting test proposed by Gittleman et al. [18] calls for the application of 0 to $5 \mathrm{~V}$ of potential sweeps to expose the critical soft short in a fuel cell by escalating the soft short into a hard short after the membrane is conditioned at $95^{\circ} \mathrm{C}$ and $0 \% \mathrm{RH}$ in nitrogen gas for 1 hour. The critical soft short can be reached by the stepwise increase of the fuel cell compression after each 1-hour conditioning and potential cycling step.

The above mentioned tests represent some of the so called accelerated stress tests (AST) that are designed to accelerate the degradation rate for certain failure mode by controlling the severity of 
the specific stressor. Through such ASTs, one can improve the ability to predict the fuel cell lifetime or the understanding of the degradation mechanisms. Rodgers et al [19] has reviewed more ASTs and the underlying membrane degradation mechanisms that these ASTs were designed for. In this article, they correlated the AST results with fuel cell lifetimes and found that many of these ASTs can indeed significantly accelerate the degradation rates. Four common methods or the combination of these are generally used in these ASTs, which include (1) high temperatures, (2) reduced humidity, (3) OCV, and (4) cycling (humidity, temperatures, voltage, freeze/thaw, and start/stop). In practice, the ASTs of single degradation modes are often sufficient as initial screening steps to select material candidates in developing fuel cell systems as they can provide a direct feedback for material developers to improve against a specific stressor. With the increasing availability of more durable membrane materials, however, there is an increasing need for even more stressful tests that can further separate these materials. There is also a need to evaluate these membranes in a realistic fuel cell condition that requires the utilization of a combination of more severe temperatures, humidities, electrochemical loads, or cycling of those stressors to achieve a greater acceleration in the durability test. In the complex mixed-mode testing, a more sophisticated diagnostic method is then required to understand the role of different stressors and how they interact with each other before leading to the ultimate membrane failure. Consider the example of an ohmic short that can generate heat and increase local temperature which accelerates chemical degradation locally and thus leads to weakening of membranes that allows cracks to form mechanically. The increased crossover through the cracks can then increase the rate of chemical degradation that exacerbates the membrane thinning and reduces the mechanical resistance to carbon fiber penetration which further worsens the ohmic shorting. As such, a vicious cycle of shorting, thinning, and cracking can take place regardless of the initiator. Because of this synergistic effect, it can be easy to misjudge the critical weakness of the membrane if solely relying on postmortem analyses. The ability to detect initiation of degradation, to distinguish modes of degradation, and to continuously monitor the progress of degradation without interrupting the 
durability test would be highly desirable if a mixed-mode durability test is to be used and a deeper understanding of the material is required. Furthermore, as fuel cells often fail by highly localized degradation, there is an additional need for a diagnostic technique that provides sufficient spatial resolution to detect the localized degradation. In this article, we will report a mixed-mode AST and a diagnostic method that can satisfy these needs.

\section{EXPERIMENTAL}

The fuel cell consisted of an MEA with carbon supported Pt catalyst $\left(0.4 \mathrm{mg}_{\mathrm{Pt}} \mathrm{cm}^{-2}\right)$ applied to an Ion Power ${ }^{\mathrm{TM}}$ N111-IP membrane $(25 \mu \mathrm{m})$ using a decal transfer method [20] and two $180 \mu \mathrm{m}$ Toray $^{\mathrm{TM}}$ TGP-H-060 gas diffusion media (GDM) coated with $25 \mu \mathrm{m}$ micro porous layers (MPL). The gas diffusion layer (GDL, i.e. GDM plus MPL) were compressed to $20 \%$ strain by the flowfields and compression plates as shown in Fig. 1. The compressive strain was controlled by two layers of Teflon gasket with a window opening to form an active area of $50 \mathrm{~cm}^{2}$. It should be noted that the N111-IP membrane is a mechanically robust membrane that can survive more than 20,000 cycles in the U.S. DOE humidity cycling test without developing a detectable leak [16].

The hardware portion of the test setup was largely the same as that reported by Gagliardo et al. [21]. The graphite cathode flowfield plate was machined to contain 9-path serpentine flow channels that were $1.12 \mathrm{~mm}$ deep and $0.84 \mathrm{~mm}$ wide, separated by $0.71 \mathrm{~mm}$ wide lands. Adjacent to the cathode flowfield plate were a copper current collector plate, a plastic insulator sheet, and then a stainless steel compression plate. The anode side of the fuel cell contained a matching graphite flowfield plate that was segmented into a 10 by 10 array containing square segments of $0.5 \mathrm{~cm}^{2}$ (Fig. 2). The flowfield segments were separated by electrically insulating and gas impermeable adhesive. A segmented printed circuit board (PCB) with a matching $10 \times 10$ array of gold contacts in the active area was in contact with the segmented anode flowfield plate. The $10 \mathrm{x}$ 
10 array of contacts was connected to calibrated shunt resistors facilitating localized current density and high-frequency resistance (HFR) measurements. Next to the segmented printed circuit board were the current collector, insulator, and compression plate. The temperature of the fuel cell was maintained by two heater rods in the compression plates and a fan external to the cell in conjunction with two thermocouples in the flow field plates.

The experiment comprised blocks of 10 hours durability testing followed by 1 hour of degradation diagnostics. During the durability testing, the electrical load was cycled between 0.08 $\mathrm{A} \mathrm{cm}^{-2}$ for 6 minutes and $0.8 \mathrm{~A} \mathrm{~cm}^{-2}$ for another 3 minutes, corresponding to stoichs of 17 and 1.7 , respectively. The cell temperature was $80^{\circ} \mathrm{C}$. Both gas streams had an $\mathrm{RH}$ of $50 \%$ at the inlets and a pressure of $300 \mathrm{kPa}_{\mathrm{abs}}$ at the outlets. Experiments were conducted in both counter- and co-flow configurations using pure $\mathrm{H}_{2}$ on the anode and air on the cathode. A key feature of the test protocol was the simplicity of test control since humidity and potential cycles were controlled entirely by cycling the electrical load while other parameters such as the temperature, gas flow rate, dew point, and pressure all remained unchanged throughout the durability testing. An important consequence of the test protocol was that it promoted various degrees and types of degradation across the membrane as some areas of the membrane would experience significantly stronger humidity and electric current cycles than others while all were subjected to the same potential cycles.

The degradation diagnostics of the experiment consisted of three steps: (1) a 20-min " $\mathrm{H}_{2}$ diffusive crossover" measurement; (2) a 10-min " $\mathrm{H}_{2}$ convective crossover" measurement, and (3) a 10-min shorting measurement, all at a cell temperature of $80^{\circ} \mathrm{C}$ and $50 \% \mathrm{RH}$ at the inlets. In Steps 1 and 2, $H_{2}$ and $N_{2}$ were fed to the anode and cathode, respectively. In Step 1, equal $H_{2}$ and $N_{2}$ pressures of $206 \mathrm{kPa}_{\text {abs }}$ were maintained while in Step 2 they were maintained at $206 \mathrm{kPa}_{\mathrm{abs}}$ and $184 \mathrm{kPa}_{\mathrm{abs}}$, respectively. The current resulting from the oxidation of the molecular crossed-over $\mathrm{H}_{2}$ at the cathode was measured by applying a constant potential of $0.5 \mathrm{~V}$ across the anode and 
cathode. This method is similar to the electrochemical hydrogen crossover method [22] adapted for the U.S. DOE chemical and mechanical degradation test protocols [5]. In Step 3, after the anode side was purged with $184 \mathrm{kPa}_{\mathrm{abs}} \mathrm{N}_{2}$, the shorting current was measured under $0.5 \mathrm{~V}$ across the cell. Note that the sequence of diagnostic steps was designed to maximize the gas purges within the hardware and to exhaust the reactant gas residue within the MEA and GDL. The crossover and shorting currents were recorded only after they reached a steady state. From these measurements, the shorting resistance $R_{\text {short }}$, diffusive crossover current $i_{\text {diff }}$, and convective crossover current $i_{\text {conv }}$ can be determined using Eqs. (1-3) as follows.

$$
\begin{aligned}
& R_{\text {short }}=\frac{0.5 \mathrm{~V}}{i^{\text {Step } 3}} \\
& i_{\text {diff }}=i^{\text {Step } 1}-i^{\text {Step } 3} \\
& i_{\text {conv }}=i^{\text {Step } 2}-i^{\text {Step } 1}
\end{aligned}
$$

where $i$ with the superscripts represents the current density measured at the corresponding step. By comparing the diffusive crossover current with that measured at the beginning of the test (denoted BOT), $i_{d i f f}^{B O T}$, and assuming negligible change in $\mathrm{H}_{2}$ diffusivity, one can determine the remaining local average membrane thickness $h_{P E M}$ by

$$
h_{P E M}=\frac{i_{\text {diff }}^{B O T}}{i_{\text {diff }}} h_{P E M}^{B O T}
$$

Finally, the $\mathrm{H}_{2}$ mass leak rate $m_{\mathrm{H} 2}$ through pinholes which is attributed to convection under the 22 $\mathrm{kPa}$ pressure bias on the anode side, is given by

$$
\mathrm{m}_{\mathrm{H}_{2}}=\frac{i_{\text {conv }} \times M W_{\mathrm{H}_{2}}}{2 \times F}
$$

where $\mathrm{MW}_{\mathrm{H} 2}$ is the molecular weight of $\mathrm{H}_{2}$ and $\mathrm{F}$ is Faraday's constant. It should be noted that the 
mass flow rate $m_{H 2}$ can be easily converted to volumetric flow rate in terms of standard cubic center per minute $(\mathrm{sccm})$ at a standard condition of $0^{\circ} \mathrm{C}$ and $101 \mathrm{kPa}_{\mathrm{abs}}$. In this article, we will use the volumetric flow rate when discussing the hydrogen leak rates.

\section{RESULTS AND DISCUSSIONS}

\section{Counter-Flow Test}

Figure 3 shows a 36-min snapshot of the cell current density and 1-kHz high frequency resistance (HFR). Cycling between 0.08 and $0.8 \mathrm{~A} \mathrm{~cm}^{-2}$, the fuel cell membrane experiences dry-wet hydration cycles which are indicated by the HFR cycles between 0.16 and $0.06 \Omega \mathrm{cm}^{2}$. During the up transient from 0.08 to $0.8 \mathrm{~A} \mathrm{~cm}^{-2}$, the product water quickly hydrates the membrane and reduces the HFR. On the other hand, during the down transient, the dryout of the membrane is more gradual, as indicated by the slower increase of HFR. Although the HFR profiles during cell dryouts vary somewhat from cycle to cycle, the difference in the membrane water content is actually quite small at such high HFRs. Overall, the membrane hydration conditions from cycle to cycle are consistent.

Figure 4 shows two snapshots of the current distribution maps at 0.08 and $0.8 \mathrm{~A} \mathrm{~cm}^{-2}$, representing dry and wet conditions, respectively. At the dry condition of $0.08 \mathrm{~A} \mathrm{~cm}^{-2}$, the 100 segments within the $50 \mathrm{~cm}^{2}$ active area have a current density range from 0.045 to $0.116 \mathrm{~A} \mathrm{~cm}^{-2}$ and a standard deviation of $0.017 \mathrm{~A} \mathrm{~cm}^{-2}$. At the wet condition of $0.8 \mathrm{~A} \mathrm{~cm}^{-2}$, the current density ranges from 0.45 to $1.06 \mathrm{~A} \mathrm{~cm}^{-2}$ and the standard deviation is $0.15 \mathrm{~A} \mathrm{~cm}^{-2}$. The current distribution at the dry condition is relatively uniform but at the wet condition, it is highly non-uniform. The area near the anode or the cathode inlet has a lower current density and is dryer at the wet condition compared to the area in the middle section. The result suggests that the middle section of the cell 
experiences stronger current and hydration cycling compared to the inlets. Because the different amplitude of current and hydration cycles throughout the cell, one would expect the cell to have various degrees of degradation at different locations. It should be noted that although the cell temperature are well maintained in the flowfield plates, due to the thermal resistance from the membrane to the flowfield through the electrodes and GDL and interfaces between those layers, one would expect that the non-uniform current distribution at the wet condition would result in some temperature non-uniformity while the uniform current distribution at the dry condition should lead to uniform membrane temperature distribution. Although the distribution and cycling of membrane temperature may have an effect on the membrane durability, this topic has not been investigated and would be left as an opportunity for future studies.

Figure 5 illustrates the average cell shorting and hydrogen crossover current histories during the test. The shorting current remains relatively constant, suggesting no significant short developed during the test. The magnitudes of hydrogen crossover currents measured during both Step 1 (denoted as "shorting+diffusive") and Step 2 (denoted as "shorting+diffusive+convective") show noticeable increases throughout the test at a constant rate up to $t=6600 \mathrm{~min}$. Furthermore, the hydrogen crossover currents from Steps 1 and 2 are the same before the $t=6600$ min mark, but begin to diverge after that. In the last two diagnoses, the hydrogen crossover during Step 2 significantly outpaces that in Step 1, suggesting a significant amount of hydrogen is crossing over through pinholes. Less than 10 hours after the final diagnosis, the test was aborted due to an excessively low cell voltage at $0.8 \mathrm{~A} \mathrm{~cm}^{-2}$. A total of 900 cycles are required to fail the N111-IP membrane. It should be noted that the mechanically robust N111-IP membrane can endure more than 20,000 humidity cycles without developing pinhole failure in the U.S. DOE humidity cycling test [5]. Compared to the failure at 1800 cycles reported by Gittleman et al. [15] who applied a constant $0.1 \mathrm{~A} \mathrm{~cm}^{-2}$ using the cycling pattern of 2 -min $10 \% \mathrm{RH}$ followed by 2 -min $150 \% \mathrm{RH}$, the counter-flow test in this study has further accelerated the durability testing of N111-IP membrane. It 
should be noted that for a more conductive membrane, one may further increase the severity of degradation stressors by decreasing the $\mathrm{RH}$ of the reactant gases or increasing the cell temperature, which would be difficult to achieve using tests based on externally controlled $\mathrm{RH}$ cycling due to the difficulty associating with attaining a high $\mathrm{RH}$ at a high temperature.

Figures 6 and 7 illustrate the thinning $(\mu \mathrm{m})$, crossover leak rate $\left(10^{-3} \mathrm{sccm} \mathrm{cm}^{-2}\right)$, and shorting resistance $\left(\mathrm{k} \Omega \mathrm{cm}^{2}\right)$ maps at $\mathrm{t}=6600$ and $8000 \mathrm{~min}$, respectively. The maps at $\mathrm{t}=6600 \mathrm{~min}$ provide a snapshot of membrane's health before a significant amount of pinholes develop. On the other hand, the maps at $\mathrm{t}=8000 \mathrm{~min}$ provide a clear indication to how the membrane ultimately failed. Although in both Figs. 6(c) and 7(c) the shorting maps show no shorting resistance below $0.2 \mathrm{k} \Omega$ $\mathrm{cm}^{2}$, the shorting resistance in most segments do deteriorate moderately from $\mathrm{t}=6600$ to $8000 \mathrm{~min}$. In contrast, the maps in Figs. 6(a) and 7(a) show significant thinning, which concentrates at the first (upper) half of the cell from the anode inlet (i.e. the cathode outlet). From $t=6600$ to $8000 \mathrm{~min}$, the thinning region spreads in size and increases in magnitude. At $t=6600 \mathrm{~min}$, the thinning in some areas is more than $8 \mu \mathrm{m}$. However, even under such a severe thinning, only a few locations shown in Fig. 6 (b) develop detectable small leaks that are still less than $2 \times 10^{-3} \mathrm{sccm} \mathrm{cm}^{-2}$. At $\mathrm{t}=8000 \mathrm{~min}$ as shown in Fig. 7(b), significant leaks occur in the first half of the cell from the anode inlet, where leak rates at several locations exceed more than $50 \times 10^{-3} \mathrm{sccm} \mathrm{cm}^{-2}$. The result suggests that pinholes have formed and progressed rapidly in the 1400 minutes between the two diagnoses.

To validate the thinning and leak rate measurements, we have conducted additional measurements using alternate methods during and after the test. The exhaust water from both the anode and cathode of the fuel cells was collected to measure the release rate of various anions during the stress test. The water samples were analyzed with a Dionex DX-600 ion chromatograph. Since the fluoride loss represents the shortening of the PFSA polymer backbone, polytetrafluoroethylene $\left(-\mathrm{C}_{2} \mathrm{~F}_{4}\right)_{\mathrm{n}}$, the total fluoride inventory loss should be proportional to the 
membrane's volume loss. In a membrane constrained in plane, the decrease in volume due to fluoride inventory loss should equal the percent thickness decrease. Based on this relationship, we can verify the $\mathrm{H}_{2}$ diffusive crossover measurement by comparing the membrane volume loss from the fluoride emission measurement and that from the average membrane thinning determined by integrating the local thinning over the 100 current distribution segments. Figure 8 shows the good agreement in membrane's volume loss calculated from these two independent methods. In Fig. 8, the cell leak rate calculated by integrating the local leak rate over the 100 segments is also plotted, showing that the fuel cell does not develop an appreciable leak until $t=7300$ min and that the final diagnosis has a cell leak rate of $1 \mathrm{sccm}$. At the end of the test, a $21 \mathrm{kPa}$ pressure differential of air was applied between the anode and cathode to measure the physical leak rate. An 8 sccm leak confirms that a significant leak has indeed occurred, as indicated by the $\mathrm{H}_{2}$ crossover leak. Since pinholes can grow in an accelerated fashion, it is not surprising to see a higher leak rate from the physical leak test with about an additional 10 hours of testing after the final diagnosis.

After the physical leak test, the MEA was removed and subjected to two postmortem analyses. The first was a bubble pinhole test, in which the MEA was fixed in place and flooded with water on the top surface, lightly pressurized with air underneath, and air bubble leakage was observed using a stereo light microscope. The locations of the emerging air bubbles were recorded to construct a pinhole map. The second postmortem analysis was a cross-sectional thickness measurement using light microscopy. Using the thinning map of Fig. $7(b)$ as a guide, membrane samples were taken from 10 locations corresponding to those from the $1^{\text {st }}$ to $10^{\text {th }}$ row along the $5^{\text {th }}$ column from the anode inlet. They were then potted with epoxy, polished, and imaged at multiple locations within each sample. Multiple thickness measurements were made within each image. Average, as well as minimum and maximum, thicknesses were then recorded.

Figure 9 illustrates the superposition of the leak rate map with the bubble pinhole map. The bubble 
pinhole map has confirmed the leaks in the three most severely leaking locations in the crossover leak map near the $5^{\text {th }}$ column of the $3^{\text {rd }}$ row, the $2^{\text {nd }}$ column of the $5^{\text {th }}$ row, and the $7^{\text {th }}$ column of the $5^{\text {th }}$ row. One discrepancy between the two maps is found along the $2^{\text {nd }}$ row of the segments. Although this discrepancy may be caused by additional damage to the sample from the MEA removal process, the exact cause is not known. In spite of this, it is encouraging that the bubble pinhole test confirms the pinhole locations predicted from the convective crossover measurement.

Figure 10 compares the remaining membrane thickness in the segments along the $5^{\text {th }}$ column in Fig. 7(b) using the crossover current measurement and the postmortem cross-sectional microscopy. The remaining membrane thickness decreases from the anode outlet (cathode inlet) toward the anode inlet (cathode outlet). Significant variations in the remaining thickness are seen as the $10^{\text {th }}$ segment at the location $95 \%$ from the anode inlet has almost no thinning while the $3^{\text {rd }}$ segment at the $25 \%$ location has the most thinning of more than $15 \mu \mathrm{m}$. The cross-sectional measurement confirms the highly non-uniform thinning in the degraded membrane as the excellent agreement is seen in all except the $3^{\text {rd }}$ segment where the remaining thickness based on the diffusive crossover measurement is $5 \mu \mathrm{m}$ more than that from the cross-sectional measurement. Since the durability test did not stop until about 10 hours after the final crossover current diagnosis, the discrepancy at the $3^{\text {rd }}$ segment may be caused by the additional degradation time. It is interesting to see that by referring to Fig. 4 , the location of the maximum thinning falls in the area of the strongest current and hydration cycling. On the other hand, the cathode inlet areas which stay relatively dry due to the weakest current and hydration cycling have resulted in the least thinning even though it is well known that dryer conditions tend to promote more chemical degradation than wetter conditions. The result from this test suggests that humidity cycling may promote stronger chemical degradation than dry or wet condition alone.

The unique ability to simultaneously measure the thinning and leak rate at up to 100 locations in 
this study has offered an intriguing way to study the synergy and the correlation between different degradation modes. Figure 11 shows the leak rate versus membrane thinning at all segments from each degradation diagnosis. When the run time is less than $6600 \mathrm{~min}$, no leak is detected even at a thinning of $11 \mu \mathrm{m}$. At $\mathrm{t}=7300 \mathrm{~min}$, the correlation between the thinning and leak rate shows that leaks occur when membrane thinning is greater than about $7 \mu \mathrm{m}$. Beyond that, the more severe the thinning, the larger the leak rate. At $t=8000 \mathrm{~min}$, the threshold thinning to initiate leaks has decreased to around $4 \mu \mathrm{m}$. The decreasing threshold thinning suggests that with additional hygrothermal stress cycles, the membrane is mechanically degraded so that pinholes can form at a lower degree of chemical degradation. Finally at $t=8000 \mathrm{~min}$, it is found that the correlation between the leak and thinning is relatively poor. The poor correlation may be caused by the pinhole size variation since the crack growth in a highly chemically degraded and thus embrittled membrane material is likely to be unstable.

\section{Co-Flow Test}

Figure 12 shows two current distribution snapshots of the durability test conducted in the co-flow configuration under the 0.08 and $0.8 \mathrm{~A} \mathrm{~cm}^{-2}$ electrical loads. The current distribution map at the dry condition of $0.08 \mathrm{~A} \mathrm{~cm}^{-2}$ is very similar to that in Fig. 4(a) for the counter-flow test as both show uniform current distribution over the whole cell. On the other hand, the current distribution maps between the counter- and co- flow configurations are vastly different under the wet condition of 0.8 $A \mathrm{~cm}^{-2}$. In the co-flow configuration, both anode and cathode gas streams become more humid flowing downstream as they are continuously supplied with product water. As the increasing water in both gas streams hydrates the membrane in between, its proton transport resistance is reduced. The local current density increases from the inlet to outlet as seen in Fig. 12(b). The monotonically increasing current and membrane hydration make the mechanical and chemical stressors in the co-flow configuration easier to control and predict. In contrast, the current distribution in the 
counter-flow test configuration (see Fig. 4) features areas of lower current density near both inlet and outlet regions compared to the middle section. Since the current distribution as well as membrane hydration in the counter-flow configuration will strongly depend on the complicated water balance of the fuel cell, with areas of large $\mathrm{RH}$ difference across the membrane, it is believed that the mechanical and chemical stressors in this configuration would be more difficult to control and predict. Thus, from the viewpoint of experimental simplicity and degradation predictability, the co-flow configuration is more advantageous than the counter-flow configuration.

Figure 13 illustrates the average cell shorting and hydrogen crossover current histories during the test. Unlike the counter-flow test, shorting is found during the final diagnosis at $t=19100$ min of the co-flow test. Similar to the counter-flow test, the hydrogen crossover currents measured at both Steps 1 and 2 are almost identical before reaching a diverging point at $t=11900 \mathrm{~min}$. Less than 10 hours after the final diagnosis at $t=19100 \mathrm{~min}$, the test was aborted due to the excessively low cell potential. Comparing the slopes of the hydrogen crossover curves before the two $\mathrm{H}_{2}$ crossover current curves diverge in Figs. 5 and 13, the co-flow configuration has a lower rate of degradation than the counter-flow test.

Figures 14 compares the last three membrane thinning maps ( $t=8000,11200$, and $11900 \mathrm{~min})$ before significant leaks occur, which shows increasing thinning from gas inlets toward outlets. It is interesting to see the thinning distribution agrees with the current distribution shown in Fig. 12(b), suggesting strong correlation between current/hydration cycling and chemical degradation. This is also in agreement with the correlation found in the counter-flow test.

Figures 15 shows the three crossover leak maps at $t=11200,11900$, and 16600 min. In Fig. 15(a) of $t=11200$ min, only a few segments near the outlet show small leaks. At $t=11900$ min in Fig. 15(b), the area of leaks spreads out toward the inlet and increases in magnitude. At $t=16600$ min in 
Fig. 15(c), significant leaks have occurred near the gas outlets, which were later confirmed by the bubble pinhole test.

Figure 16 shows two shorting maps at $t=16600$ and 19100 min that represent the contrasting snapshots from the two consecutive diagnoses between which the membrane shorting resistance rapidly deteriorated. At $\mathrm{t}=16600 \mathrm{~min}$, the membrane is free of shorts since the shorting resistance at all segments are higher than $1 \mathrm{k} \Omega \mathrm{cm}^{2}$. On the other hand, the shorting map at $\mathrm{t}=19100 \mathrm{~min}$ shows significant shorts at the lower-right quarter of the cell near the anode/cathode outlets where many segments have a shorting resistance lower than $0.1 \mathrm{k} \Omega \mathrm{cm}^{2}$.

The sequence of degradation events summarized from Figs. 13 to 16 clearly shows that the chemical stressor is the initiator that ultimately leads to the failure of the N111-IP membrane. As the membrane is sufficiently weakened chemically while accumulating substantial mechanical damage driven by the hygrothermal fatigue stress, pinholes form. Finally, after the membrane loses its mechanical barrier against the intruding conductive elements across the membrane due to the greatly reduced thickness and open pinholes, shorts develop rapidly. Comparing the current distribution maps in Fig. 12 with the degradation maps in Figs. 14(c), 15(c), and 16(b), the strong correlation between the degree of degradation and the severity of the current/humidity cycles is clear. The result shows that increasing the amplitude and frequency of the current/humidity cycling can be a very effective way to accelerate the durability testing of the membrane. To use this approach, however, one should be aware of the synergistic effect of the degradation stressors and take care to decipher this synergy so that the true weakness of the membrane can be understood.

Figure 17 illustrates the average membrane volume loss and cell leak rate versus test run time. Again, the membrane volume loss and cell leak rate were calculated by integrating the membrane thinning and the diffusive and convective leak rates through the 100 segments of the entire cell. 
The cell does not develop appreciable leaks until the membrane loses an average of $13 \%$ (or 3.3 $\mu \mathrm{m})$ of the thickness. In spite of different eventual failure times and thinning/leak distributions, this result is on par with that from the counter-flow test as seen in Fig. 8, which shows the membrane does not leak until it loses an average of $18 \%$ (or $4.5 \mu \mathrm{m}$ ) of the thickness.

Figure 18 shows the leak rate versus membrane thinning for all segments at each degradation diagnosis up to $t=11900$ min when appreciable leaks are seen. Similar to the counter-flow test, the co-flow result also shows that the threshold thinning to initiate leaks is reduced as the test run time increases. The result again suggests that the membrane's eventual failure from pinholes is a result of the interplay between the chemical and mechanical degradations: the more mechanical degradation, the less chemical degradation is required to develop pinholes, and vice versa.

\section{CONCLUSION}

We have developed a mixed-mode accelerated stress test by applying current cycling between 0.08 and $0.8 \mathrm{~A} \mathrm{~cm}^{-2}$. The test condition had induced both voltage cycling as well as hydration cycling. The test was shown to accelerate the failure of a mechanically robust membrane, Ion Power ${ }^{\top \mathrm{M}}$ N111-IP. To quantify the degree of degradation and to differentiate degradation modes, we utilized an in-situ shorting/crossover diagnostic method to periodically determine the shorting resistance, thinning, and crossover leak rate of the membrane as the test progressed. Results from the in-situ diagnostics agreed well with conventional diagnostic metrics such as fluoride release rates and physical crossover leak rates. Applying this diagnostic procedure in a specialized segmented fuel cell fixture that provided 100 local current density measurements via a 10 by 10 array of flowfield segments over $50 \mathrm{~cm}^{2}$ of active area, we were able to monitor the degradation progression and map the three basic types of degradation within the membrane. The degradation maps of thinning and crossover leaks were validated by membrane 
thickness measurements using cross-sectional microscopy and pinhole bubble test. From the viewpoint of achieving the greatest reduction in test times, the co-flow configuration is preferred. However, the greatly simplified current and humidity distribution and a more predictable failure location within the cell that is combined with still significant test time reduction may make the coflow configuration an attractive option for many. Although the use of segmented fuel cell fixture has greatly increased the ability of understanding degradation behavior and is highly recommended if available, it is believed that the accelerated testing and diagnostic methodology demonstrated in this article without the use of current distribution tool should be sufficient to provide a viable test method to enable the durability testing of robust membranes beyond the existing tests recommended by U.S. DOE in most fuel cell labs.

\section{ACKNOWLEDGMENTS}

The authors would like to thank Bhaskar Sompalli for help in the fuel cell durability tests; Rob Reid for assistance in the use of current distribution tool; Brian Litteer for performing postmortem cross-sectional microscopy and pinhole analysis; Wenbin Gu for help in the development of crossover diagnostics; Frank Coms for consultation in chemical degradation mechanisms; and Craig Gittleman for valuable inputs on membrane degradation mechanisms and the U.S. DOE tests. 


\section{REFERENCES}

1 W. Liu, M. Crum, Effective Testing Matrix for Studying Membrane Durability in PEM Fuel Cells: Part I. Chemical Durability, ECS Transactions, 3(1) (2006) 531-540

2 H. Liu, J. Zhang, F. Coms, W. Gu, B. Litteer, H. Gasteiger, Impact of Gas Partial Pressure on PEMFC Chemical Degradation, ECS Trans. 3(1) (2006) 493-505.

3 T. Kinumoto, M. Inaba, Y. Nakayama, K. Ogata, R. Umebayashi, A. Tasaka, Ya. Iriyama, T. Abe, Z. Ogumi, Durability of Perfluorinated lonomer Membrane Against Hydrogen Peroxide, J. Power Sources, 158(2) (2006) 1222-1228.

4 M. Inaba, H. Yamada, R. Umebayashi, M. Sugishita, A. Tasaka, Membrane Degradation in Polymer Electrolyte Fuel Cells under Low Humidification Conditions, Electrochemisty 75 (2007) 207-212.

5 C.S. Gittleman, Automotive Perspective on PEM Evaluation, DOE High Temperature Membrane Working Group, Washington, DC, 2009, http://www1.eere.energy.gov/hydrogenandfuelcells/pdfs/htmwg may09 automotive perspe ctive.pdf.

6 Y.H. Lai, C.K. Mittelsteadt, C.S. Gittleman, D.A. Dillard, Viscoelastic stress model and mechanical characterization of perfluorosulfonic acid (PFSA) polymer electrolyte membranes, J. Fuel Cell Sci. Technol. 6 (2009) 021002-2 - 021002-13.

7 K.A. Patankar, D.A. Dillard, S.W. Case, M.W. Ellis, Y.H. Lai, M.K. Budinski, C.S. Gittleman, Hygrothermal characterization of the viscoelastic properties of Gore-Select® 57 proton exchange membrane, Mech. Time-Depend Mater. 12 (2008) 221-236.

8 D.A. Dillard, Y. Li, J.R. Grohs, S.W. Case, M.W. Ellis, Y.H. Lai, M.K. Budinski, C.S. 
Gittleman, On the use of pressure-loaded blister tests to characterize the strength and durability of proton exchange membranes, J. Fuel Cell Sci. Technol. 6 (2009) 031014-1 031014-8.

9 Y. Li, J.R. Grohs, M.T. Pestrak, D.A. Dillard, S.W. Case, M.W. Ellis, Y.H. Lai, C.S. Gittleman, D.P. Miller, Fatigue and creep to leak tests of proton exchange membranes using pressure-loaded blisters, J. Power Sources 194 (2009) 873-879.

10 K.A. Patankar, D.A. Dillard, S.W. Case, M.W. Ellis, Y.H. Lai, Y. Li, M.K. Budinski, C.S. Gittleman, Characterizing fracture energy of proton exchange membranes (PEM) using a knife slit test, J. Polym. Sci., Part B: Polym. Phys. 48(3) (2010) 333-343.

11 Y. Tang, K. Kusoglu, A.M. Karlsson, M.H. Santare, M. H., S. Cleghorn, W.B. Johnson, Mechanical properties of a reinforced composite polymer electrolyte membrane and its simulated performance in PEM fuel cells, J. Power Sources 175 (2008) 817-825.

12 X. Huang, R. Solasi, Y. Zou, M. Feshler, K. Reifsnider, D. Condit, S. Burlatsky, T. Madden, Mechanical endurance of polymer electrolyte membrane and PEM fuel cell durability, J. Polym. Sci., Part B: Polym. Phys. 44 (2006) 2346-2357.

13 R. Solasi, Y. Zou, X. Huang, K. Reifsnider D. Condit, On mechanical behavior and in-plane modeling of constrained PEM fuel cell membranes subjected to hydration and temperature cycles, J. Power Sources 167 (2007) 366-377.

14 Y. Tang, A.M. Karlsson, M.H. Santare, M. Gilbert, S. Cleghorn, W.B. Johnson, An experimental investigation of humidity and temperature effects on the mechanical properties of perfluorosulfonic acid membrane, Mater. Sci. Eng., A 425 (2006) 297-304.

15 C.S. Gittleman, Y.H. Lai, D.P. Miller, Durability of Perfluorosulfonic Acid Membranes for PEM Fuel Cells, Extended Abstract, AIChE 2005 Annual Meeting, Cincinnati, OH, 2005.

16 Y.H. Lai, D.A. Dillard, Mechanical durability characterization and modeling of ionomeric 
membranes, in: W. Vielstich, H. Yokokawa, H.A. Gasteiger (Eds.), Handbook of Fuel Cells: Advances in Electrocatalysis, Materials, Diagnostics and Durability, Volumes 5 \& 6, John Wiley \& Sons, Chichester, 2009, pp. 403-419.

17 C.K. Mittelsteadt, H. Liu, Conductivity, Permeability, and Ohmic Shorting of lonomeric Membranes, in: W. Vielstich, H. Yokokawa, H.A. Gasteiger (Eds.), Handbook of Fuel Cells: Advances in Electrocatalysis, Materials, Diagnostics and Durability, Volumes 5 \& 6, John Wiley \& Sons, Chichester, 2009, pp. 345-358.

18 Gittleman, C. S., Coms, F. D., and Lai, Y. H., Membrane Durability: Physical and Chemical Degradation, Polymer Electrolyte Fuel Cell Degradation, Editors: M.M. Mench, E.C. Kumbur, T.N. Veziroglu, Elsevier Science, (2012).

19 M. P. Rodgers, L. J. Bonville, H. R. Kunz, D. K. Slattery, J. M. Fenton, Chem. Rev. 112 (2012), 6075-6103.

20 H. A. Gasteiger, W. Gu, R. Makharia, M. F. Mathias, and B. Sompalli, in Handbook of Fuel Cells: Fundamentals, Technology, and Applications, W. Vielstich, A. Lamm, and H. A. Gasteiger, Editors, Vol. 3, p. 593, John Wiley \& Sons, Hoboken, NJ (2003).

21 J.J. Gagliardo, J.P. Owejan, T.A.Trabold, and T.W.Tighe, Neutron radiography characterization of an operating proton exchange membrane fuel cell with localized current distribution measurements, Nucl. Instrum. Meth. A, 605 (2009) 115-118.

22 USFCC "Single Cell Test Protocol" Section A3-2, electrochemical hydrogen crossover method, USFCC Protocol on Fuel Cell Component Testing, 2004, http://www.usfcc.com/resources/Trans-H2Quality-Primer-04-003.pdf. 


\section{Figure Captions}

Figure 1. Exploded fuel cell assembly, including the segmented circuit board for current distribution measurement (adapted from Reference 21).

Figure 2. Photograph of the segmented graphite anode flowfield plate, which contains a 10 $x 10$ array of segments that are separated by electrically insulating and gas impermeable adhesive. The gas in/out ports are located at the lower left and upper right corners.

Figure 3. A 36-min snapshot of the cell current density and high frequency resistance (HFR) profiles during the durability test in the counter-flow configuration at a cell temperature of $80^{\circ} \mathrm{C}$ and $50 \% \mathrm{RH}$ at the inlets.

Figure 4. The current distribution maps under the cell current densities of (a) $0.08 \mathrm{~A} \mathrm{~cm}^{-2}$ and (b) $0.8 \mathrm{~A} \mathrm{~cm}^{-2}$ in the counter-flow test. The arrows in the figure represent the reactant gas flow directions at the gas inlet/outlet ports.

Figure 5. The average shorting and hydrogen crossover currents of the cell in the counterflow test. The shorting/crossover current measured at Diagnostic Steps 1, 2, and 3 are denoted as "SHORTING+DIFFUSIVE", "SHORTING+DIFFUSIVE+CONVECTIVE", and "SHORTING", respectively. Notice the currents at Steps 1 and 2 diverge at $t=7300$ min.

Figure 6. The (a) thinning, (b) leak rate, and (c) shorting maps at $t=6600$ min of the counter-flow test.

Figure 7. The (a) thinning, (b) leak rate, and (c) shorting maps at $t=8000$ min of the counter-flow test 
Figure 8. Average membrane volume loss and leak rate of the membrane from the counter-flow test. The membrane volume loss is determined from the fluoride release measurement or $\mathrm{H} 2$ diffusive crossover measurements. The leak rate is determined from physical leak test or $\mathrm{H} 2$ convective crossover measurement.

Figure 9. The comparison of the bubble pinhole map and the crossover leak map from the counter-flow test. The locations of leaks from the bubble pinhole test are represented by the solid circle symbols.

Figure 10. The comparison of the remaining membrane thickness along the 5th column of Fig. 7(a) using the crossover and microscopic cross-sectional measurements. Multiple cross-sectional thickness measurements were conducted on samples taken from each segment. The square symbol represents the mean thickness. The upper and lower tick marks represent the minimum and maximum thicknesses, respectively.

Figure 11. The correlation between the leak rate and thinning at various diagnoses from the counter-flow test. Each symbol represents the leak rate and thinning from a current distribution segment.

Figure 12. The current distribution maps under the cell current densities of (a) $0.08 \mathrm{~A} \mathrm{~cm}^{-2}$ and (b) $0.8 \mathrm{~A} \mathrm{~cm}^{-2}$ in the co-flow test. The arrows in the figure represent the reactant gas flow directions at the gas inlet/outlet ports.

Figure 13. The average shorting and hydrogen crossover currents of the cell in the co-flow test.

Figure 14. The thinning maps at (a) $t=8000 \mathrm{~min}$, (b) $t=11200 \mathrm{~min}$, and (c) $t=11900 \mathrm{~min}$ 
from the co-flow test.

Figure 15. The leak rate maps at (a) $t=11200 \mathrm{~min},(b) t=11900 \mathrm{~min}$, and (c) $t=16600 \mathrm{~min}$ in the co-flow test.

Figure 16. The shorting maps at (a) $t=16600$ min and (b) $t=19100$ min of the co-flow test.

Figure 17. The averaged membrane volume loss and leak rate over time in the co-flow test. Both volume loss and leak rate are determined from the $\mathrm{H} 2$ crossover measurement and integrated over the 100 segments.

Figure 18. The correlation between the leak rate and thinning at various diagnoses from the co-flow test. Each symbol represents the leak rate and thinning from a current distribution segment. 


\section{Compression plate}

Insulator

Current collector

Cathode flowfield plate

MEA, GDL, and seal gaskets

Anode flowfield plate

Segmented circuit board

Current collector

Insulator

Compression plate 
Figure(s)

Click here to download Figure(s): Figure 2.pdf

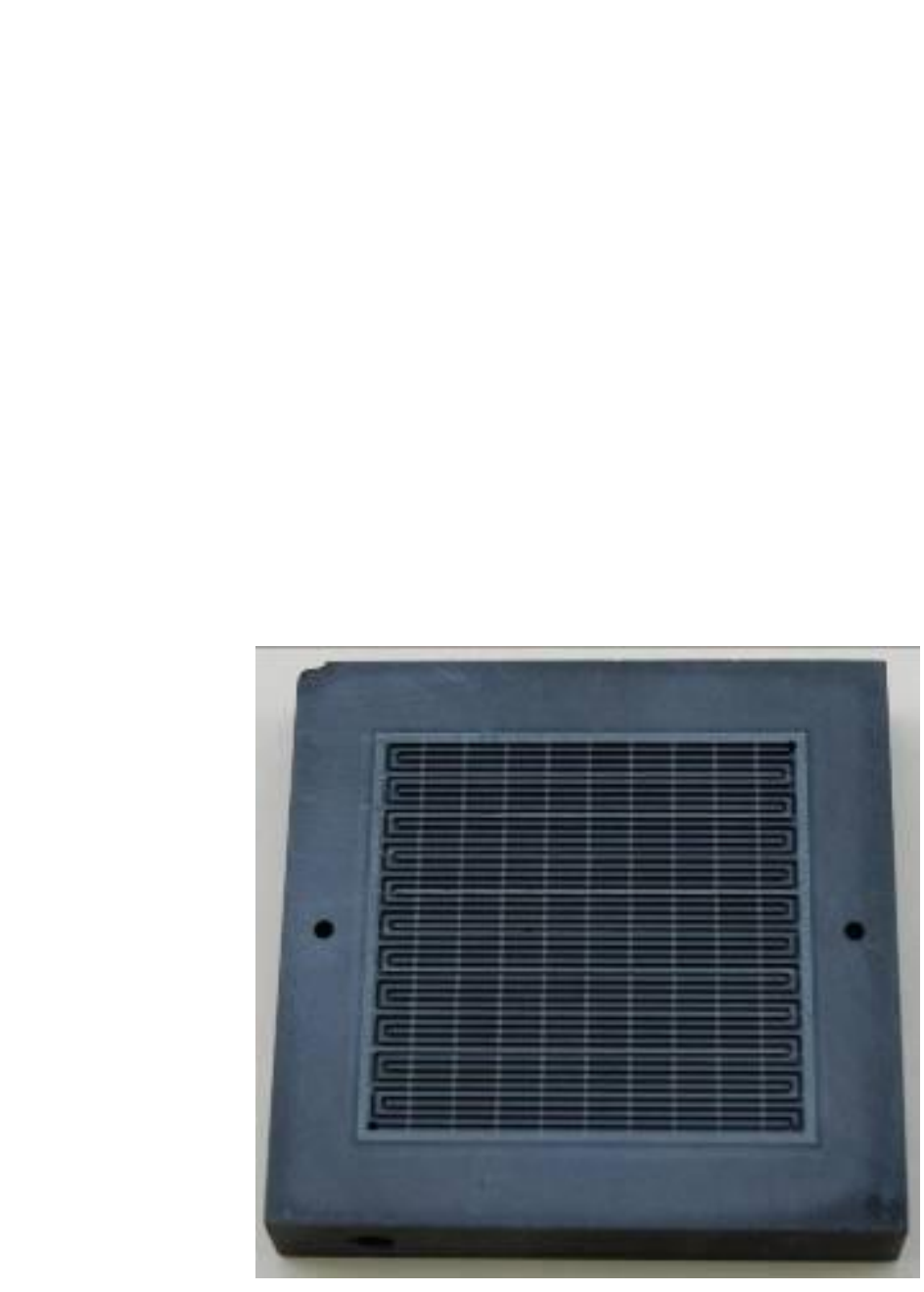

\section{Click here to download Figure(s): Figure 2.pdf}




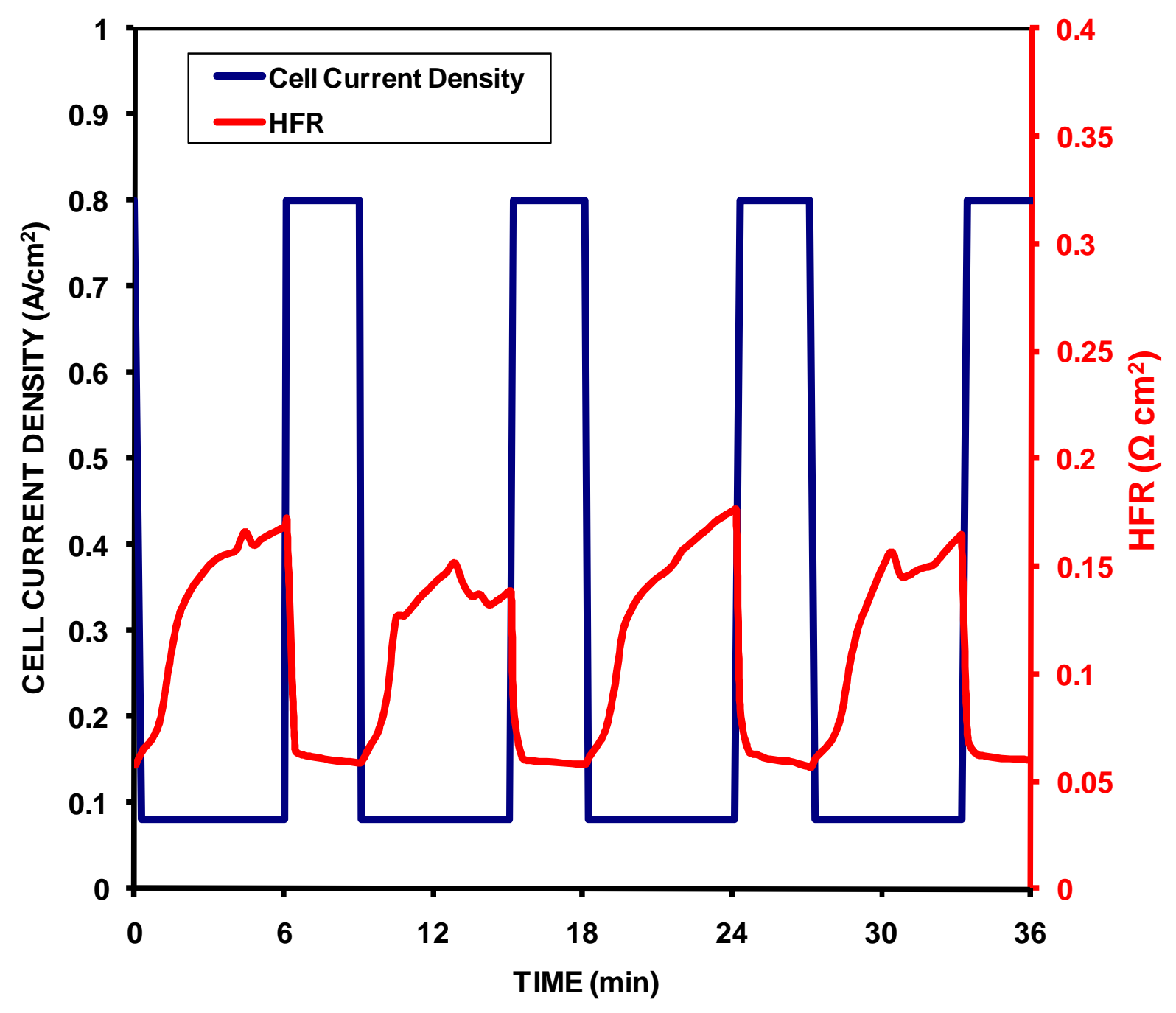


Click here to download Figure(s): Figure 4.pdf

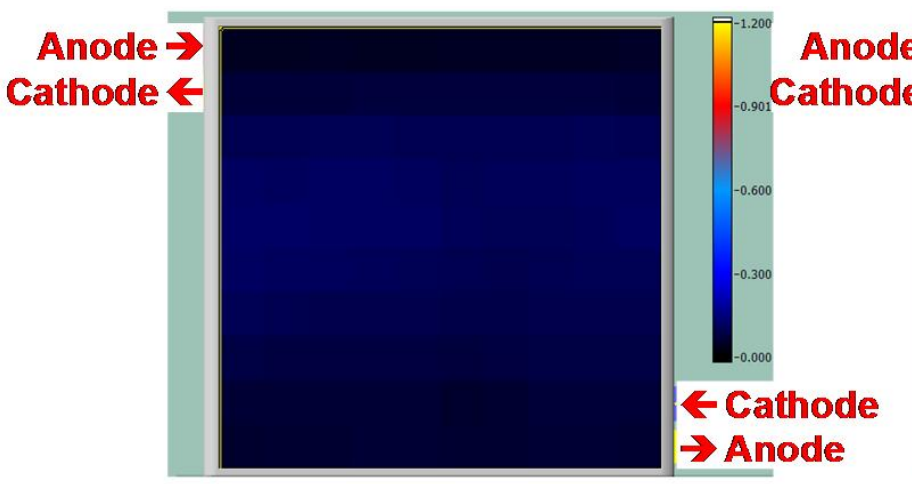

(a)

Current density map

Cell CD $=0.08 \mathrm{~A} / \mathrm{cm}^{2}$

Cell HFR $=0.16 \Omega \mathrm{cm}^{2}$

$\mathrm{CD}=0.08 \pm 0.017 \mathrm{~A} / \mathrm{cm}^{2}$

$C D$ range $=(0.045,0.116)$

"Dry condition"

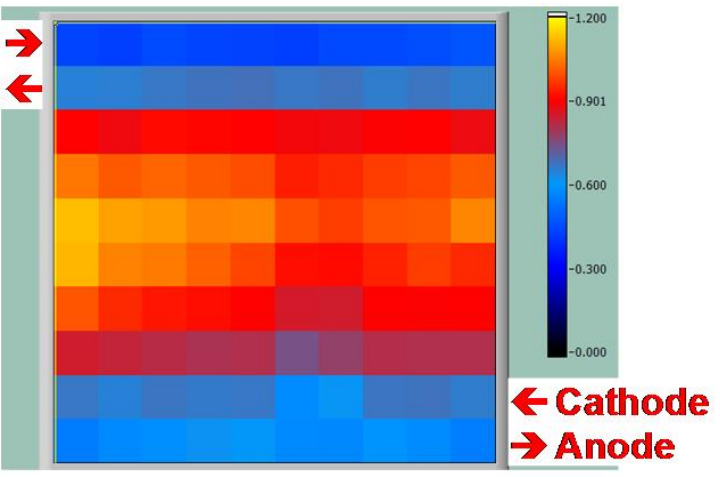

(b)

Current density map

Cell CD $=0.8 \mathrm{~A} / \mathrm{cm}^{2}$

Cell HFR $=0.055 \Omega \mathrm{cm}^{2}$

$C D=0.8 \pm 0.15 \mathrm{~A} / \mathrm{cm}^{2}$

CD range $=(0.45,1.06)$

"Wet condition" 
Click here to download Figure(s): Figure 5.pdf

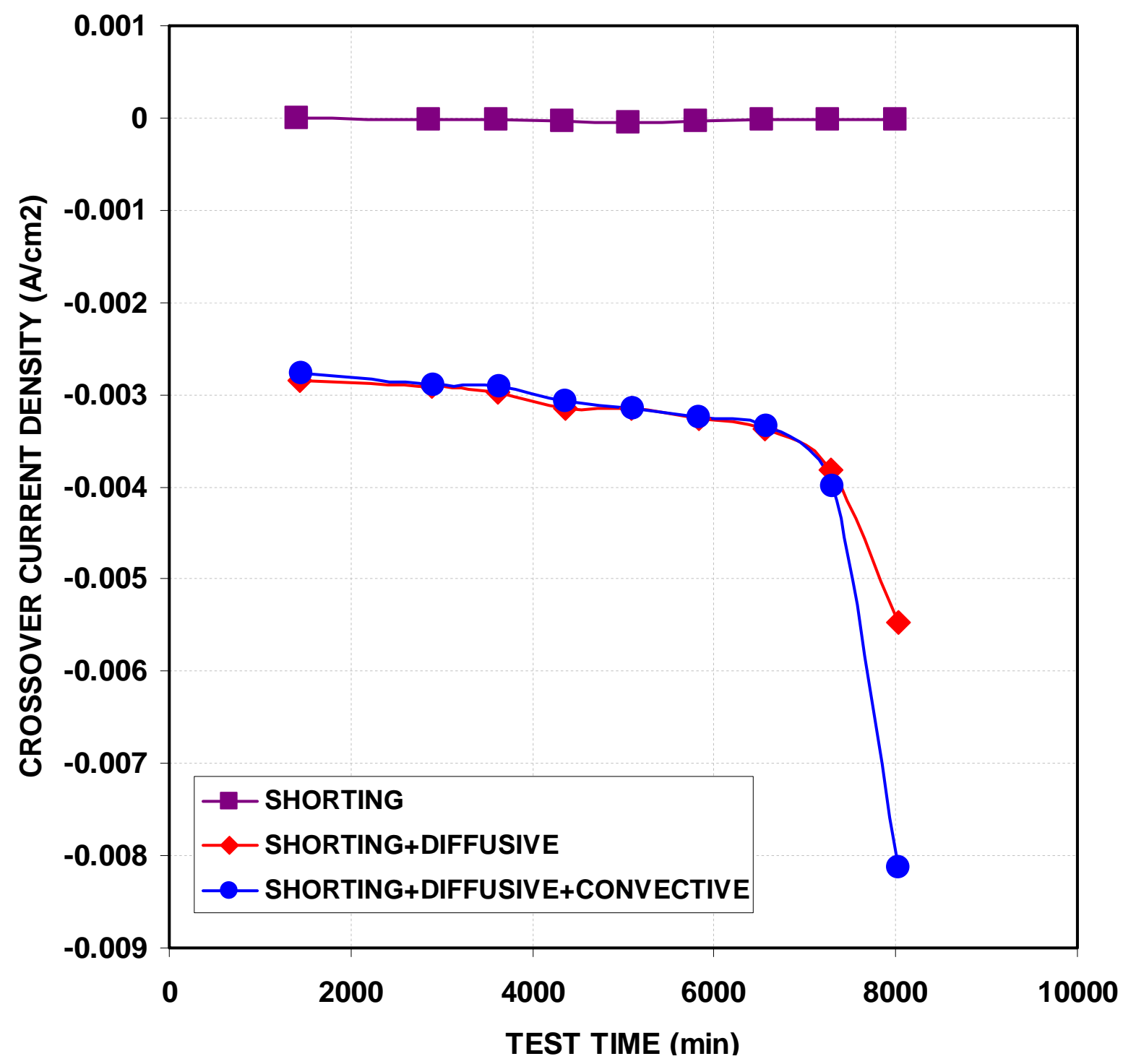


Anode In ==>

Cathode Out $<==$

\begin{tabular}{|l|l|l|l|l|l|l|l|l|l|}
\hline 4.7 & 5.4 & 6.1 & 7.4 & 6.6 & 6.4 & 6 & 5.9 & 5 & 4.6 \\
\hline
\end{tabular}

\begin{tabular}{|l|l|l|l|l|l|l|l|l|l|}
\hline 3.8 & 6.6 & 8.2 & 10 & 9.8 & 8.9 & 8.9 & 8.7 & 6.7 & 5.5 \\
\hline & & & & & & & & & \\
\hline
\end{tabular}

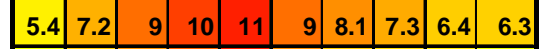

\begin{tabular}{|l|l|l|l|l|l|l|l|l|l|}
\hline 4.7 & 6.4 & 7.9 & 9.3 & 11 & 8.1 & 6.4 & 6 & 5.5 & 4.7 \\
\hline
\end{tabular}

\begin{tabular}{|l|l|l|l|l|l|l|l|l|l|}
3.8 & 5.5 & 6.5 & 6.8 & 6.6 & 6.2 & 5.5 & 5.7 & 6 & 4.3 \\
\hline & & & & & & & & & \\
\hline
\end{tabular}

(a)

\begin{tabular}{|l|l|l|l|l|l|l|l|l|l|}
\hline 3.9 & 5 & 5.9 & 5.7 & 5.1 & 4.5 & 4.3 & 4.5 & 5.1 & 3.8 \\
\hline
\end{tabular}

\begin{tabular}{|l|l|l|l|l|l|l|l|l|l|}
\hline 2.3 & 3.8 & 4.7 & 4 & 4.4 & 3.6 & 3 & 3.4 & 3.3 & 2.7 \\
\hline
\end{tabular}

\begin{tabular}{|l|l|l|l|l|l|l|l|l|l|}
\hline 2 & 2.4 & 3.6 & 3.7 & 3.3 & 3.1 & 2.9 & 2.6 & 2.5 & 2.1 \\
\hline
\end{tabular}

\begin{tabular}{|l|l|l|l|l|l|l|l|l|l|}
1.7 & 2 & 1.4 & 0.5 & 1.5 & 1.8 & 1.6 & 0.8 & 1.9 & 0.8 \\
\hline
\end{tabular}

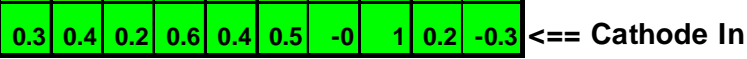

Leak Rate $\left(10^{-3} \mathrm{sccm} / \mathrm{cm}^{2}\right)$

Anode In ==>

Cathode Out $<=$

(b)

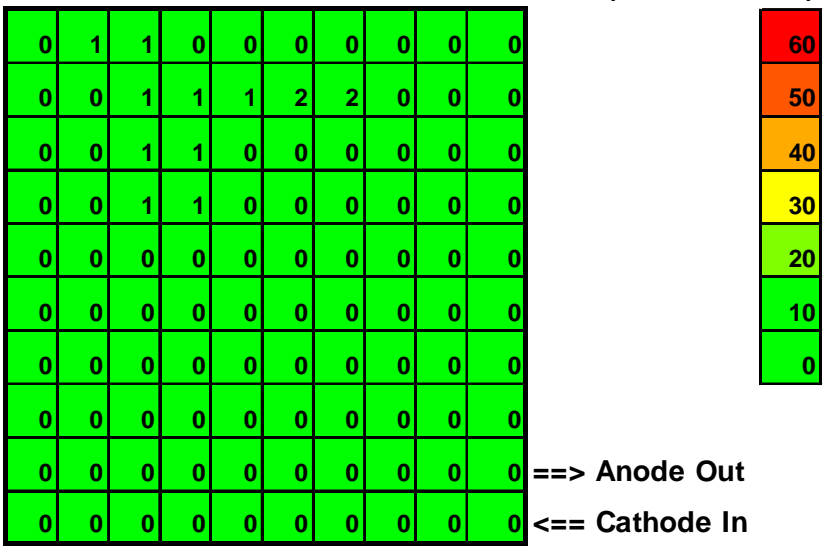

Shorting $\left(\mathrm{k} \Omega \mathrm{cm}^{2}\right)$

\begin{tabular}{|c|c|c|c|c|c|c|c|c|c|c|c|}
\hline Anode In ==> & 26 & 23 & 11 & 11 & 13 & 71 & 28 & 31 & 23 & 26 & \\
\hline \multirow{9}{*}{ Cathode Out $<==$} & 13 & 7 & 71 & 56 & 7.1 & 21 & 29 & 5.4 & 13 & 7.7 & \\
\hline & 6.7 & 6.7 & 6.3 & 19 & 42 & 71 & 23 & 8.8 & 6.4 & 8.2 & \\
\hline & 6.8 & 8.1 & 45 & 18 & 26 & 250 & 14 & 6.2 & 13 & 31 & \\
\hline & 13 & 4.9 & 125 & 21 & 17 & 83 & 6.6 & 12 & 24 & 29 & \\
\hline & 28 & 28 & 11 & 125 & 250 & 20 & 6.3 & 8.2 & 100 & 16 & \\
\hline & 10 & 14 & 11 & 13 & 250 & 125 & 71 & 8.1 & 15 & 19 & \\
\hline & 3.7 & 71 & 11 & 20 & 13 & 100 & 7.1 & 16 & $63 \mid$ & 167 & \multirow{3}{*}{$2\left|\begin{array}{l}2 \\
7\end{array}\right|==>$ Anode Out } \\
\hline & 3.8 & 4.9 & 3.9 & 5.8 & 4.1 & 7.5 & 3.3 & 7.6 & 20 & 5.2 & \\
\hline & 2.8 & 4.2 & 3.5 & 2.7 & 6 & 3.2 & 5.4 & $4.7 \mid$ & 3.9 & 2.7 & \\
\hline
\end{tabular}

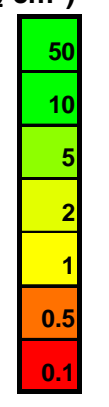

\begin{tabular}{l|l|l|l|l|l|l|l|l|l|l}
3.8 & 4.9 & 3.9 & 5.8 & 4.1 & 7.5 & 3.3 & 7.6 & 20 & 5.2 & $==>$ Anode Out
\end{tabular} 
Anode In ==>

Cathode Out <==

\begin{tabular}{|l|l|l|l|l|l|l|l|l|l|}
\hline 7.3 & 7.1 & 8.2 & 6.9 & 7.2 & 6.9 & 6.5 & 5.6 & 5.3 & 5.2 \\
\hline
\end{tabular}

\begin{tabular}{|l|l|l|l|l|l|l|l|l|l|}
\hline 8.5 & 9.8 & 10 & 10 & 10 & 9.2 & 8.4 & 7.6 & 7.2 & 6.3 \\
\hline
\end{tabular}

\begin{tabular}{|l|l|l|l|l|l|l|l|l|l|}
9.3 & 12 & 13 & 14 & 11 & 9.8 & 9 & 8.6 & 7.3 & 5.5 \\
\hline
\end{tabular}

\begin{tabular}{|l|l|l|l|l|l|l|l|l|l|}
\hline 8.6 & 9.5 & 12 & 14 & 10 & 7.9 & 7.4 & 6.8 & 5.6 & 4.1 \\
\hline
\end{tabular}

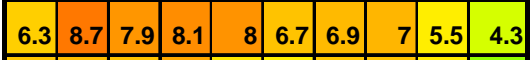

(a)

\begin{tabular}{|l|l|l|l|l|l|l|l|l|l|}
6.6 & 6.9 & 6.7 & 7.4 & 5.7 & 5.4 & 6.6 & 6.7 & 5.5 & 3.3 \\
\hline
\end{tabular}

\begin{tabular}{|l|l|l|l|l|l|l|l|l|l|}
\hline 5.5 & 6.8 & 6.1 & 5.9 & 4.5 & 4.1 & 4.7 & 4.3 & 3.8 & 3.6 \\
\hline
\end{tabular}

\begin{tabular}{|l|l|l|l|l|l|l|l|l|l|}
\hline 2.5 & 4.3 & 4.1 & 2.2 & 3 & 4.1 & 3.1 & 3.5 & 3.6 & 2.8 \\
\hline
\end{tabular}

\begin{tabular}{|l|l|l|l|l|l|l|l|l|l|}
2.2 & 1.5 & 0.9 & 1.6 & 1.5 & 2.6 & 1.3 & 2 & 2.2 & 1.5 \\
\hline
\end{tabular}

\begin{tabular}{|l|l|l|l|l|l|l|l|l|l|}
\hline 2.2 & 1.2 & 1.4 & 1.1 & 0.8 & 1.1 & 1.8 & 0.3 & 1 & 0.7
\end{tabular}$<==$ Cathode In

Leak Rate $\left(10^{-3} \mathrm{sccm} / \mathrm{cm}^{2}\right)$

Anode In ==>

Cathode Out $<==$

(b)

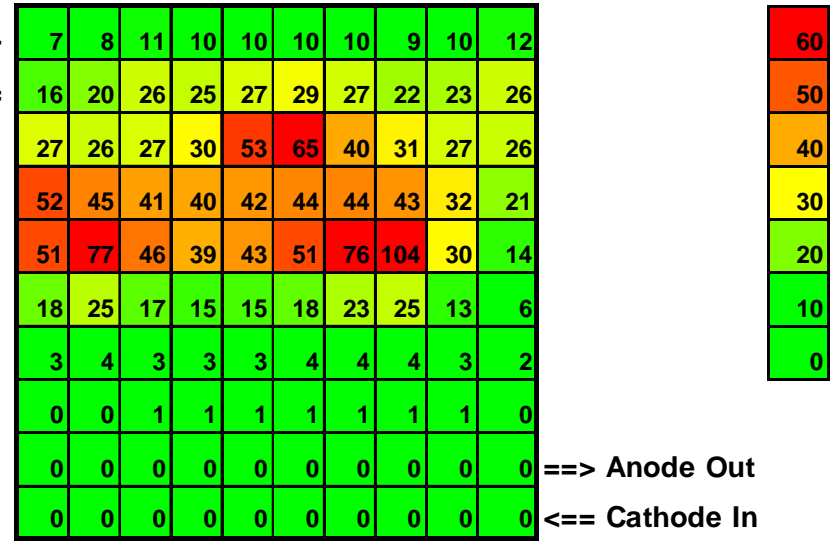

Shorting $\left(\mathrm{k}_{\Omega} \mathrm{cm}^{2}\right)$

Anode In ==>

\begin{tabular}{|l|l|l|l|l|l|l|l|l|l|}
\hline 1.2 & 1.9 & 2.3 & 1.7 & 56 & 5 & 2.4 & 2.2 & 1.3 & 15 \\
\hline
\end{tabular}

Cathode Out $<==$

\begin{tabular}{|l|l|l|l|l|l|l|l|l|l|}
2.2 & 3.9 & 1.6 & 1.7 & 14 & 1.7 & 7.1 & 14 & 5.8 & 2.7 \\
\hline
\end{tabular}

\begin{tabular}{|l|l|l|l|l|l|l|l|l|l|}
\hline 1.9 & 0.6 & 4.3 & 0.7 & 1.3 & 63 & 1.7 & 5.4 & 4.3 & 2.1 \\
\hline
\end{tabular}

(c)
Thinning ( $\mu \mathrm{m})$

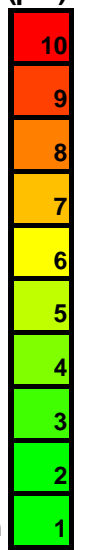

\begin{tabular}{|r|}
\hline 60 \\
\hline 50 \\
\hline 40 \\
\hline 30 \\
\hline 20 \\
\hline 10 \\
\hline 0 \\
\hline
\end{tabular}

\begin{tabular}{|r|}
\hline 50 \\
\hline 10 \\
\hline 5 \\
\hline 2 \\
\hline 1 \\
\hline 0.5 \\
\hline 0.1 \\
\hline
\end{tabular} \begin{tabular}{l|l|l|l|l|l|l|l|l|l|}
4.6 & 0.7 & 19 & 1.9 & 3.5 & 1.4 & 6.2 & 5.6 & 1.7 & 167 \\
\hline & 6.2 & 2.4 & 6.8 & 20 & 14 & 4.6 & & 1.2 & 2.2 \\
\hline
\end{tabular} \begin{tabular}{|l|l|l|l|l|l|l|l|l|l|}
\hline 3 & 6.2 & 2.4 & 6.8 & 20 & 14 & 4.6 & 1 & 3.2 & 2.2 \\
\hline
\end{tabular} \begin{tabular}{r|r|r|r|r|r|r|r|r|r|}
2.1 & 1.6 & 1.2 & 1.4 & 7.6 & 31 & 2.9 & 2.2 & 1 & 1.3
\end{tabular}$==>$ Anode Out \begin{tabular}{l|l|l|l|l|l|l|l|l|l|l}
1.6 & 1.3 & 2.4 & 1.4 & 28 & 0.8 & 1.1 & 3.1 & 1.2 & 0.5 & $<==$ Cathode In
\end{tabular} 
Click here to download Figure(s): Figure 8.pdf

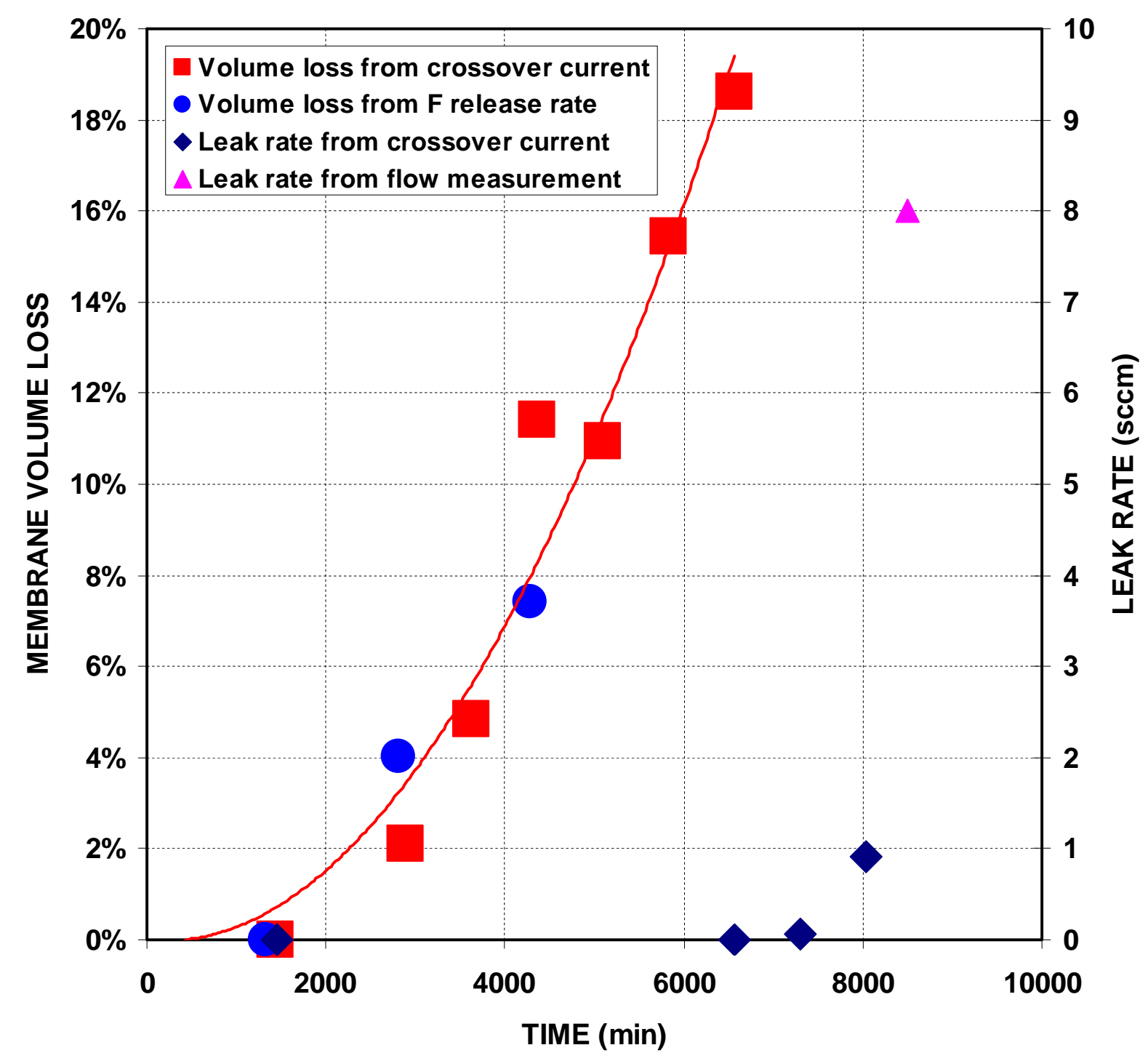


Click here to download Figure(s): Figure 9.pdf

Leak Rate $\left(10^{-3} \mathrm{sccm} / \mathrm{cm} 2\right)$

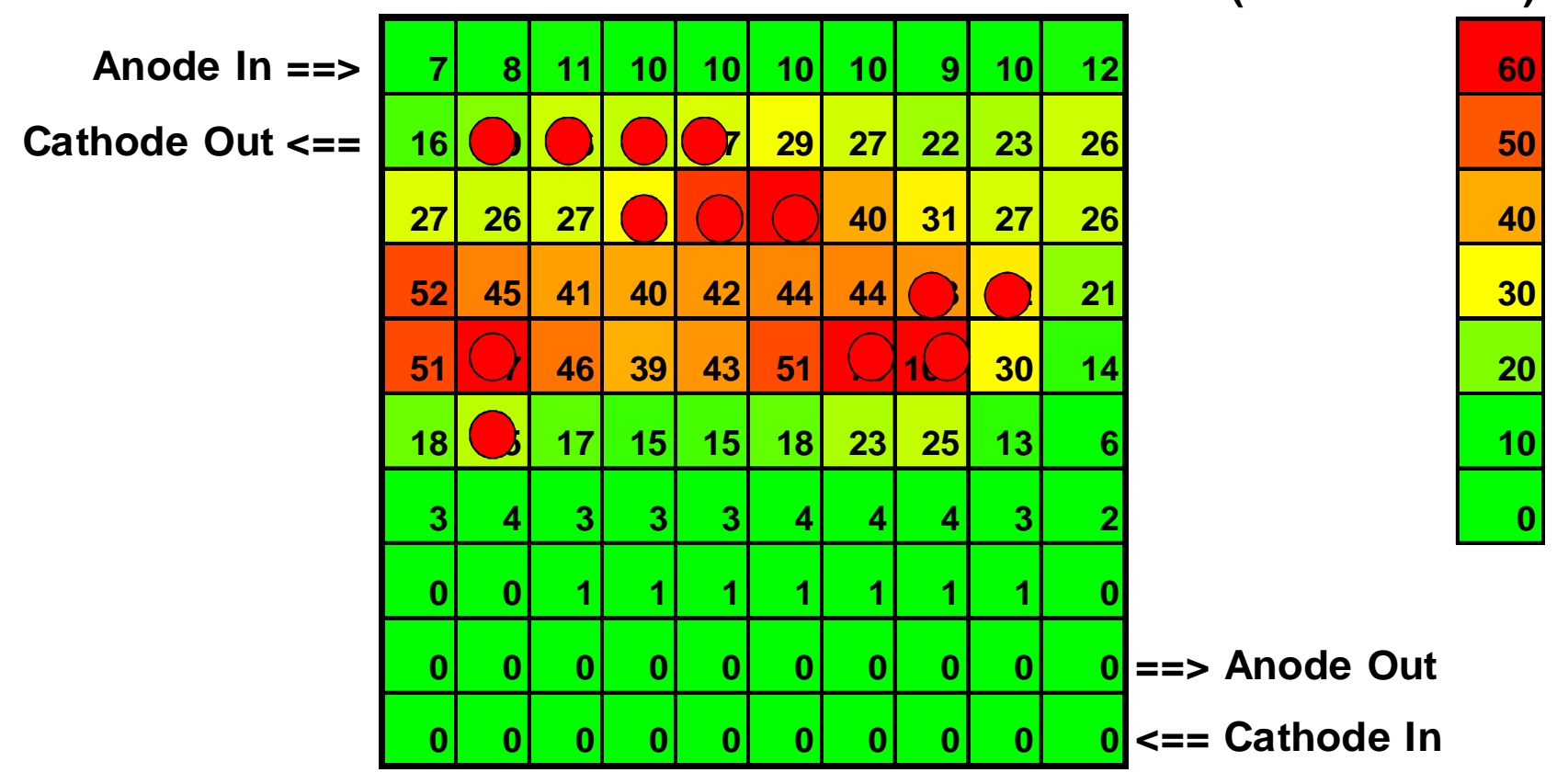


Click here to download Figure(s): Figure 10.pdf

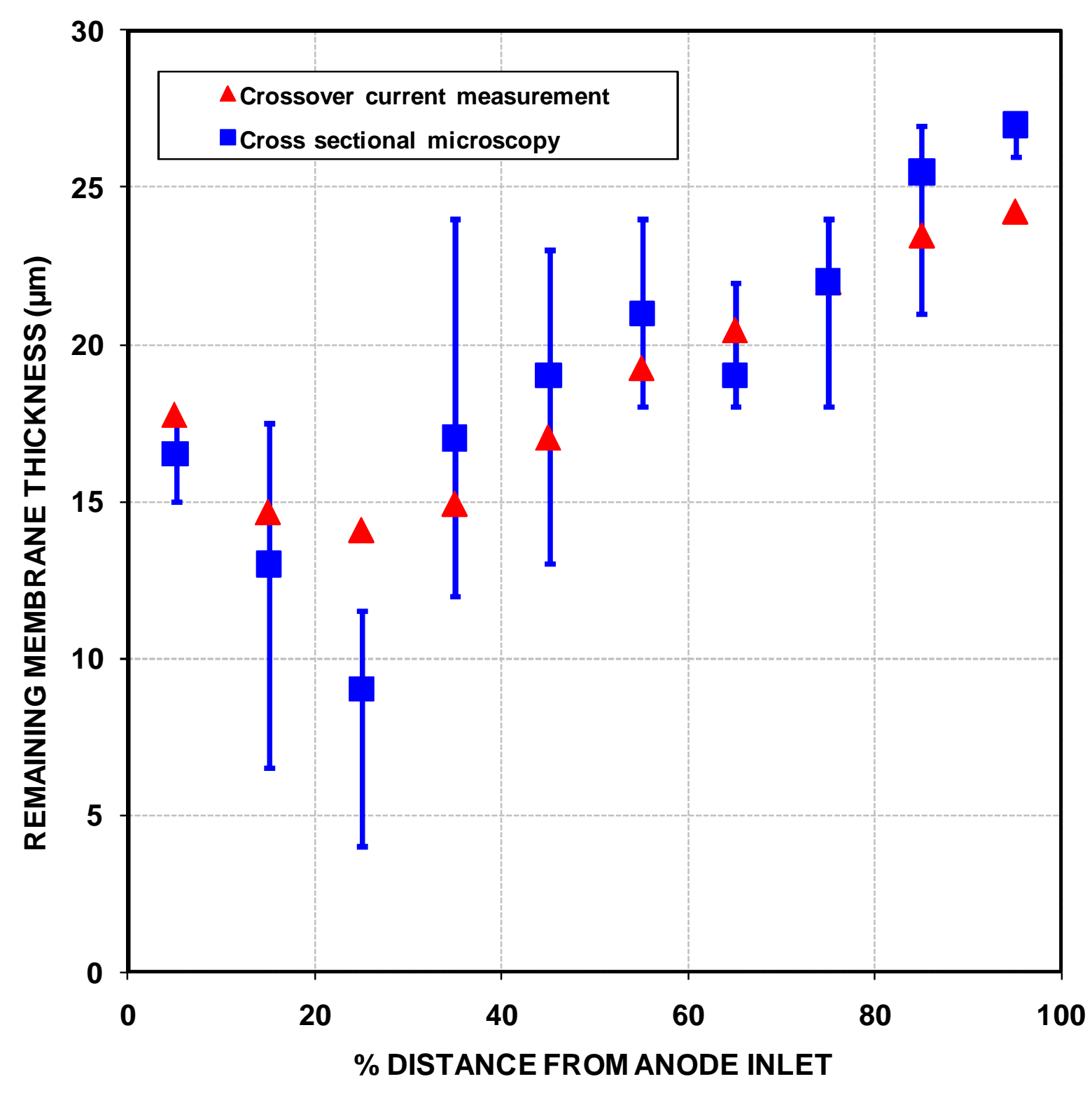




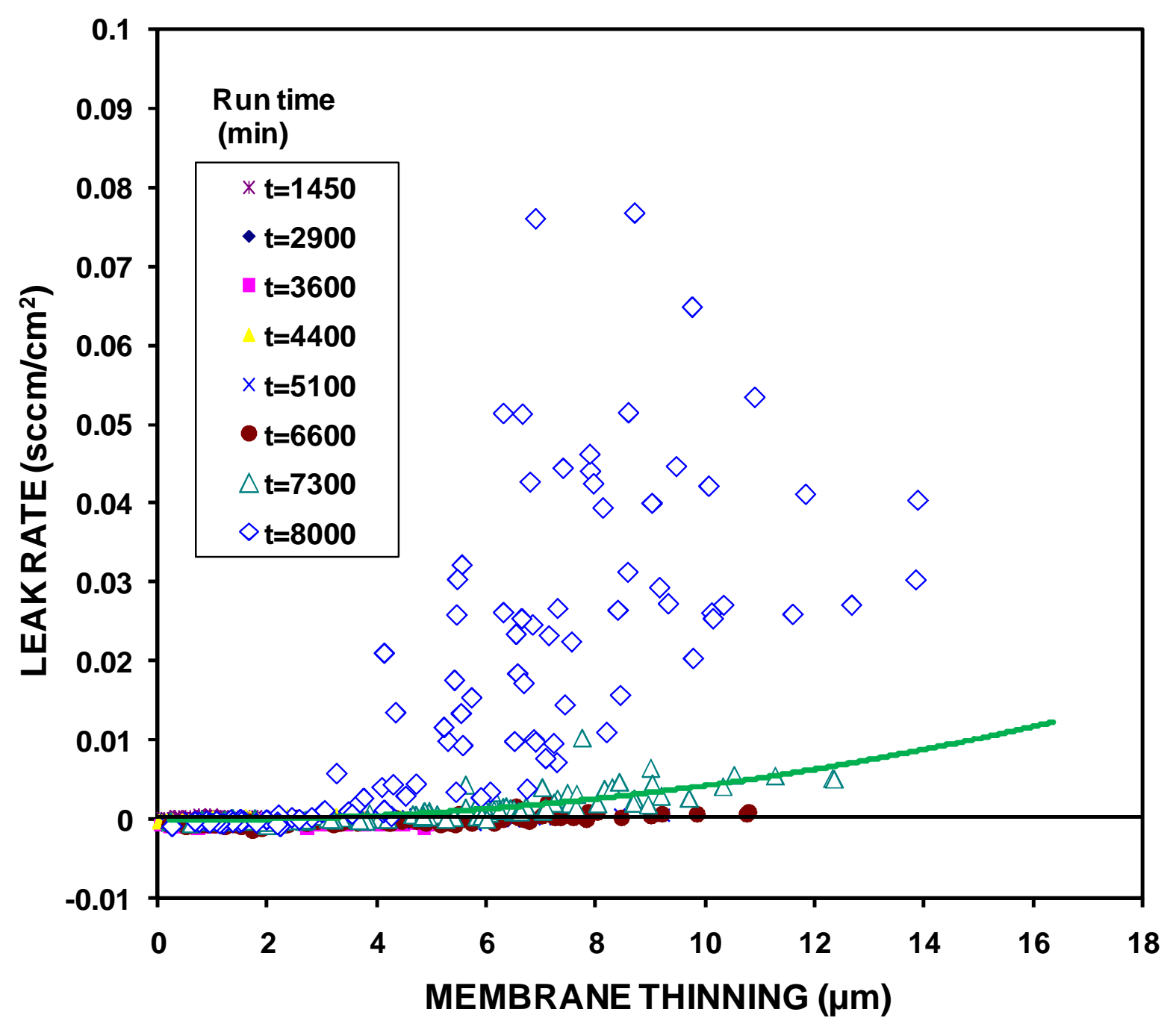




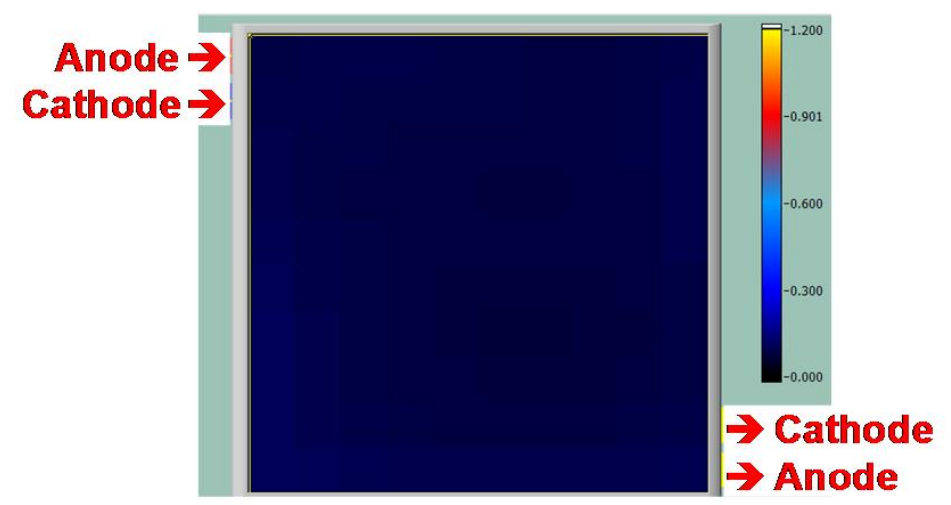

(a)

Current density map

Cell CD $=0.08 \mathrm{~A} / \mathrm{cm}^{2}$

Cell HFR $=0.170 \Omega \mathrm{cm}^{2}$

$C D=0.08 \pm 0.008 A / \mathrm{cm}^{2}$

CD range $=(0.069,0.105)$

"Dry condition"

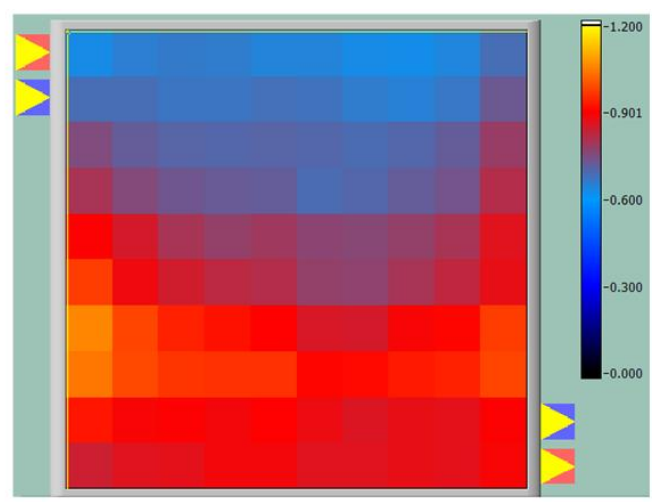

(b)

Current density map

Cell CD $=0.8 \mathrm{~A} / \mathrm{cm}^{2}$

Cell HFR $=0.078 \Omega \mathrm{cm}^{2}$

$C D=0.8 \pm 0.11 \mathrm{~A} / \mathrm{cm}^{2}$

CD range $=(0.63,1.06)$

"Wetcondition" 


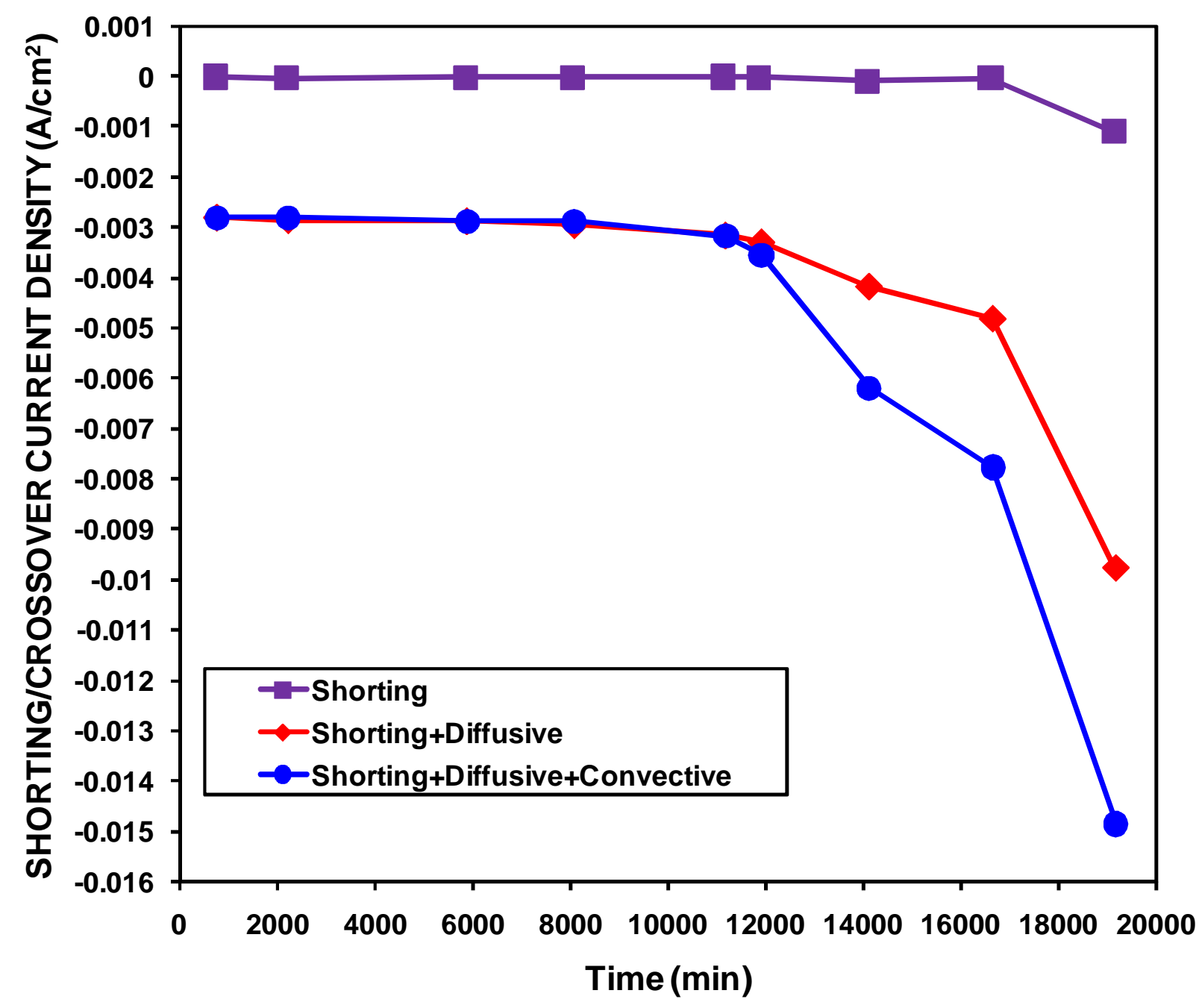




\begin{tabular}{|c|c|c|c|c|c|c|c|c|c|c|c|}
\hline \multirow{2}{*}{$\begin{aligned} \text { Anode } \ln ==> \\
\text { Cathode } \ln ==>\end{aligned}$} & 1.4 & 3.2 & 0.6 & 1.1 & 1.1 & 1.2 & 0.6 & 0.4 & 1.5 & 2 & \\
\hline & 1.8 & 0.5 & 0.4 & 0 & 0.2 & 0.2 & 0.4 & 0.4 & 0.7 & 0.7 & \\
\hline & 1.3 & 0.8 & 0.4 & 0.6 & 0.3 & 0.5 & 0.5 & 0.2 & 0.1 & 0.6 & \\
\hline & 0.4 & 1.4 & 1.2 & 0 & 1.8 & 0.1 & 1 & 1.2 & 0.4 & 1 & \\
\hline & 0.5 & 1.2 & 1.8 & 0.9 & 1.2 & 0.7 & 1.1 & 0.6 & 1.4 & 1.2 & \\
\hline & 0.7 & 1.5 & 0.9 & 0.9 & 0.5 & 1.4 & 1.3 & 1.7 & 1 & 1.5 & \\
\hline & 1.3 & 1.7 & 2.3 & 2.9 & 1.9 & 3.2 & 2.4 & 2.4 & 2.1 & 2.4 & \\
\hline & 3 & 2 & 2.2 & 3.8 & 3.4 & 3.8 & 3.6 & 3.8 & 4.1 & 3.3 & \\
\hline & 3.2 & 1.9 & 2.8 & 3.3 & 3.8 & 4.6 & 4.3 & 4.3 & 4.1 & 3.7 & $==>$ Anode Out \\
\hline & 2.8 & 1.5 & 2.3 & 2.5 & 2.9 & 3.3 & 3.5 & & 4.3 & 3.2 & $==>$ \\
\hline
\end{tabular}

\begin{tabular}{|c|c|c|c|c|c|c|c|c|c|c|c|c|}
\hline \multirow{3}{*}{ Anode In ==> } & \multicolumn{10}{|c|}{ 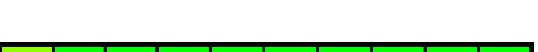 } & \multicolumn{2}{|c|}{ Thinning $(\mu \mathrm{m})$} \\
\hline & 3.3 & 1.1 & 0.1 & 0.4 & 0.7 & 0 & 0.2 & 0.7 & 0.5 & 0.7 & & \\
\hline & 0.2 & 0.1 & 1 & 1 & 0.7 & 0.1 & 1.1 & $0.7 \mid$ & 0.1 & 0.6 & & \\
\hline & 0.9 & 1.5 & 1.3 & 1.7. & 1.5 & 0.8 & 0.7 & 0.6 & 1.5 & 1.4 & & \\
\hline & 1.3 & 1.6 & 2. & 1.3 & 2.1 & 1.7 & 1.6 & 1.6 & 1.6 & 2 & & \\
\hline & 1.3 & 1.7 & 2.4 & 1.9 & 2 & 1.9 & 2.2 & 2.2 & 2.6 & 2.4 & & \\
\hline & 1.9 & 2.2 & 1.9 & 2.3 & 2.3 & 2.3 & 2.4 & 2.6 & 2.9 & 2.8 & & \\
\hline & 2.2 & 2.5 & 3.5 & 4.5 & 4 & 4.9 & 4.8 & 5.3 & 6.6 & 6 & & \\
\hline & 4.7 & 3.6 & 4.5 & 5.6 & 5.7 & 6.7 & 6.6 & 7.9 & 12 & 9.3 & & \\
\hline & 6.6 & 3.5 & 4.5 & 5.9 & 5.9 & 7 & 7.3 & 7.6 & 9.2 & 9 & $==>$ Anode Out & \\
\hline & 6.9 & 4 & 4.6 & 5.1 & 5.4 & 6 & 6.8 & 7.8 & 9.9 & 13 & $==>$ Cathode Ou & \\
\hline & & & & & & & & & & & Thinning $(\mu \mathrm{r}$ & \\
\hline Anode In ==> & \begin{tabular}{|l|}
3.8 \\
\end{tabular} & 2 & 0.8 & \begin{tabular}{|l|}
0.7 \\
\end{tabular} & 1.2 & 0.1 & 0 & 1.1 & 0.9 & 2.6 & & \\
\hline Cathode In ==> & 1.1 & 0.3 & 0.4 & 0.1 & 1 & 0.4 & 0.8 & 0.8 & 2.1 & 0.1 & & \\
\hline & 0.6 & 1.4 & 0.4 & 1.6 & 2.7 & 1.5 & 1 & 0.8 & 0.6 & 0.3 & & \\
\hline & 0.5 & 1.5 & 1.5 & 1.2 & 1.8 & 0.3 & 1.4 & 1.7 & 0.7 & 1.7 & & \\
\hline & 1.6 & 1.2 & 2.6 & 1.5 & 2 & 1.7 & 2 & 1.9 & 2.2 & 1.9 & & \\
\hline & 1.9 & 2.6 & 1.9 & 2.2 & 2 & 2.6 & 1.9 & 2.7 & 2.9 & 2.9 & & \\
\hline & 2.3 & 3.9 & 3.8 & 4.7 & 4.3 & 5.3 & 5.2 & 6.3 & 7.3 & 6.3 & & \\
\hline & 5.3 & 7.2 & 5.4 & 6.3 & 6.2 & 7.3 & 7.2 & 9.1 & 13 & 10 & & \\
\hline & 7.7 & 8.1 & 7.1 & 7.3 & 7.7 & 8.3 & 9 & 9.8 & 12 & 12 & $==>$ Anode Out & \\
\hline & 8.5 & 6.9 & 6.8 & 7.4 & 7.9 & 8.3 & 9.4 & 11 & $14 \mid$ & 16 & $==>$ Cathode O & \\
\hline
\end{tabular}


Leak Rate $\left(10^{-3} \mathrm{sccm} / \mathrm{cm}^{2}\right)$

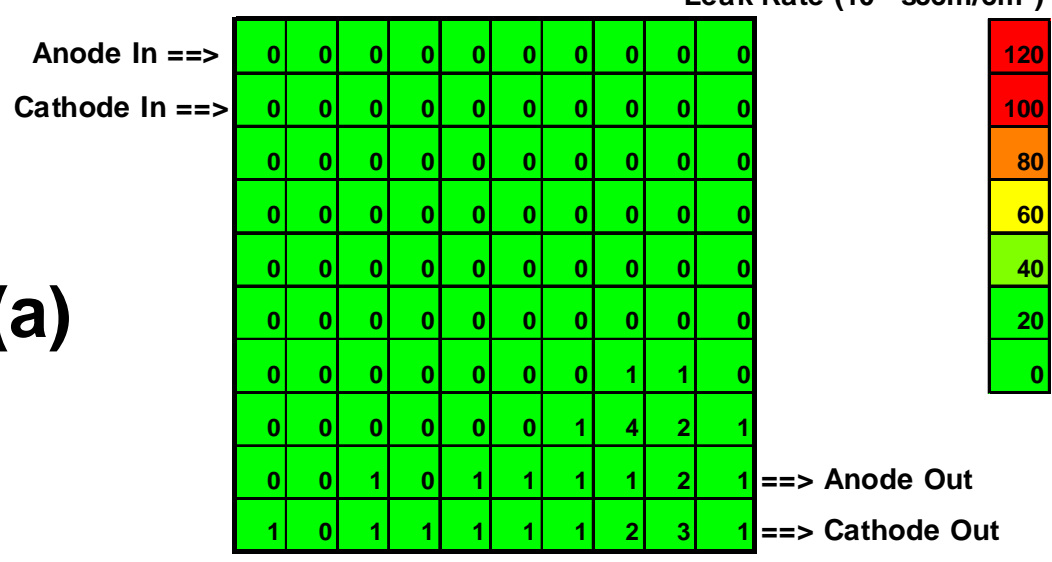

Leak Rate $\left(10^{-3} \mathrm{sccm} / \mathrm{cm}^{2}\right)$

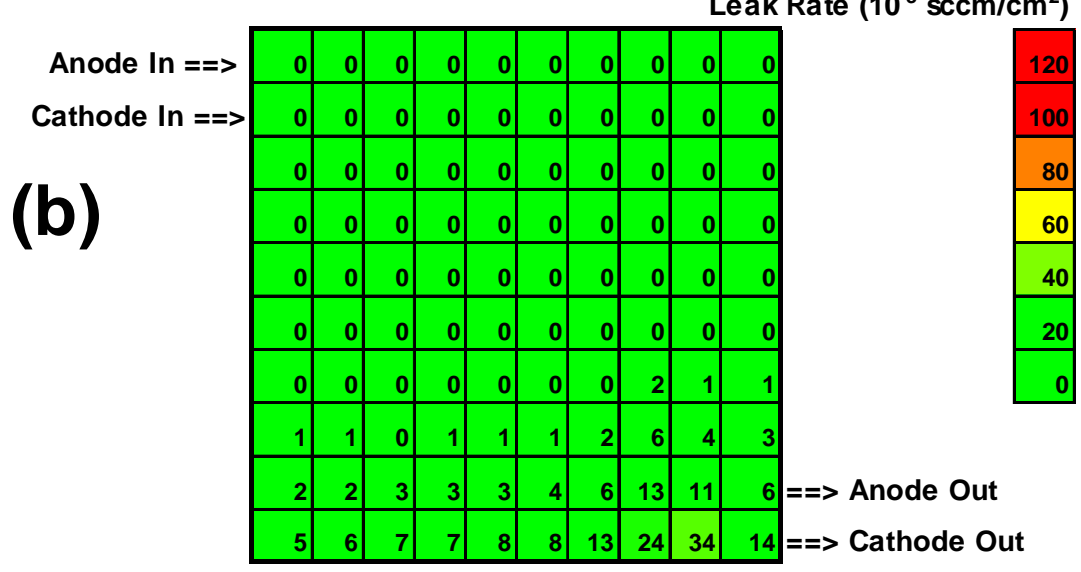

Leak Rate $\left(10^{-3} \mathrm{sccm} / \mathrm{cm}^{2}\right)$

\begin{tabular}{|c|c|c|c|c|c|c|c|c|c|c|c|}
\hline \multirow{10}{*}{$\begin{array}{c}\text { Anode In ==> } \\
\text { Cathode In }==>\end{array}$} & 0 & 0 & 0 & 0 & 0 & 0 & 0 & 0 & 0 & 2 & \\
\hline & 0 & 0 & 0 & 0 & 0 & 0 & 0 & 0 & 0 & 3 & \\
\hline & 0 & 0 & 0 & 0 & 0 & 0 & 0 & 0 & 0 & 2 & \\
\hline & 0 & 0 & 0 & 0 & 0 & 0 & 0 & 0 & 0 & 3 & \\
\hline & 0 & 0 & 0 & 0 & 0 & 0 & 0 & 0 & 1 & 3 & \\
\hline & 2 & 1 & 1 & 1 & 1 & 2 & 2 & 2 & 2 & 4 & \\
\hline & 9 & 7 & 5 & 5 & 6 & 7 & 11 & 11 & 10 & 9 & \\
\hline & 36 & 24 & 16 & 16 & 18 & 20 & 27 & 37 & 34 & 23 & \\
\hline & 73 & 57 & 54 & 56 & 63 & 74 & 106 & 174 & 87 & 51 & $==>$ Anode Out \\
\hline & 71 & 69 & 68 & 69 & 73 & 81 & 105 & 148 & 146 & 77 & $==>$ Cathode Ou \\
\hline
\end{tabular}


Shorting (k $\Omega \mathrm{cm}^{2}$ )

\begin{tabular}{|c|c|c|c|c|c|c|c|c|c|c|c|}
\hline & \multirow{3}{*}{\begin{tabular}{|l|l|}
50 \\
10
\end{tabular}} \\
\hline Anode In ==> & 71 & 7.2 & 17 & 18 & 14 & 11 & 28 & 14 & 13 & 500 & \\
\hline \multirow[t]{9}{*}{ Cathode In ==> } & 28 & 12 & 26 & 71 & 10 & 8.9 & 29 & 5.6 & 62 & 23 & \\
\hline & 28 & 7.7 & 125 & 56 & 42 & 12 & 10 & 29 & 5.4 & 7.9 & 5 \\
\hline & 45 & 63 & 167 & 13 & 83 & 24 & 9.3 & 10 & 22 & 11 & 2 \\
\hline & 16 & 8.8 & 167 & 100 & 23 & 8.2 & 6.7 & 100 & 21 & 45 & 1 \\
\hline & 71 & 56 & 38 & 83 & 23 & 22 & 63 & 42 & 13 & 15 & 0.5 \\
\hline & 15 & 125 & 24 & 25 & 23 & 8.9 & 11 & 167 & 13 & 125 & 0.1 \\
\hline & 6 & 8.5 & 8.5 & 5.4 & 9.4 & 6.7 & 36 & 71 & 50 & 31 & \\
\hline & 3.3 & 12 & 4.8 & 1.1 & 1.5 & 7.7 & 83 & 17 & 23 & 6.9 & \multirow{2}{*}{$\begin{array}{l}==>\text { Anode Out } \\
==>\text { Cathode Out }\end{array}$} \\
\hline & 13 & 4.5 & 5.6 & 8.3 & 5 & 8.1 & 45 & 22 & 25 & 14 & \\
\hline
\end{tabular}

Shorting (k $\left.\Omega \mathrm{cm}^{2}\right)$

\begin{tabular}{|c|c|c|c|c|c|c|c|c|c|c|c|}
\hline \multirow{2}{*}{$\begin{array}{l}\text { Anode In ==> } \\
\text { Cathode In ==> }\end{array}$} & 11 & 125 & 17 & 14 & 8.1 & 9.1 & 4.7 & 5.2 & 14 & 5.4 & \multirow{2}{*}{\begin{tabular}{|l|l}
50 \\
\cline { 2 - 3 } \\
\cline { 2 - 3 }
\end{tabular}} \\
\hline & 15 & 15 & 33 & 14 & 2.8 & $|3.7|$ & 5.2 & 3.7 & 4.6 & 3.4 & \\
\hline & 9.3 & 1.6 & 33 & 31 & 13 & 8.9 & 4.8 & 6.3 & 4 & 3.6 & \\
\hline & 19 & 83 & 83 & 125 & 16 & 8.2 & 3.8 & 6.8 & 7.8 & 4.6 & 2 \\
\hline & 2.7 & 6 & 26 & 8.2 & 2.9 & 2.6 & 2 & 3 & 6.3 & 2.6 & 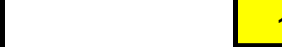 \\
\hline & 167 & 45 & 7.5 & 1.9 & 1.4 & 1 & 0.9 & 0.9 & 1.9 & 1.5 & 0. \\
\hline & 167 & 71 & 1.6 & 0.7 & 0.3 & 0.2 & 0.2 & 0.2 & 0.3 & 0.6 & 0. \\
\hline & 9.6 & 4.2 & 1.1 & 0.4 & 0.1 & .04 & 0.1 & 0.1 & 0.1 & 0.3 & \\
\hline & 6.3 & 5.3 & 1.3 & 0.3 & 0.1 & 0.1 & 0.1 & 0.1 & 0.1 & 0.3 & $==>$ Anode Out \\
\hline & 4.5 & 3.8 & 1.3 & 0.7 & 0.3 & 0.2 & 0.2 & 0.3 & 0.4 & 0.6 & $==>$ Cathode Out \\
\hline
\end{tabular}




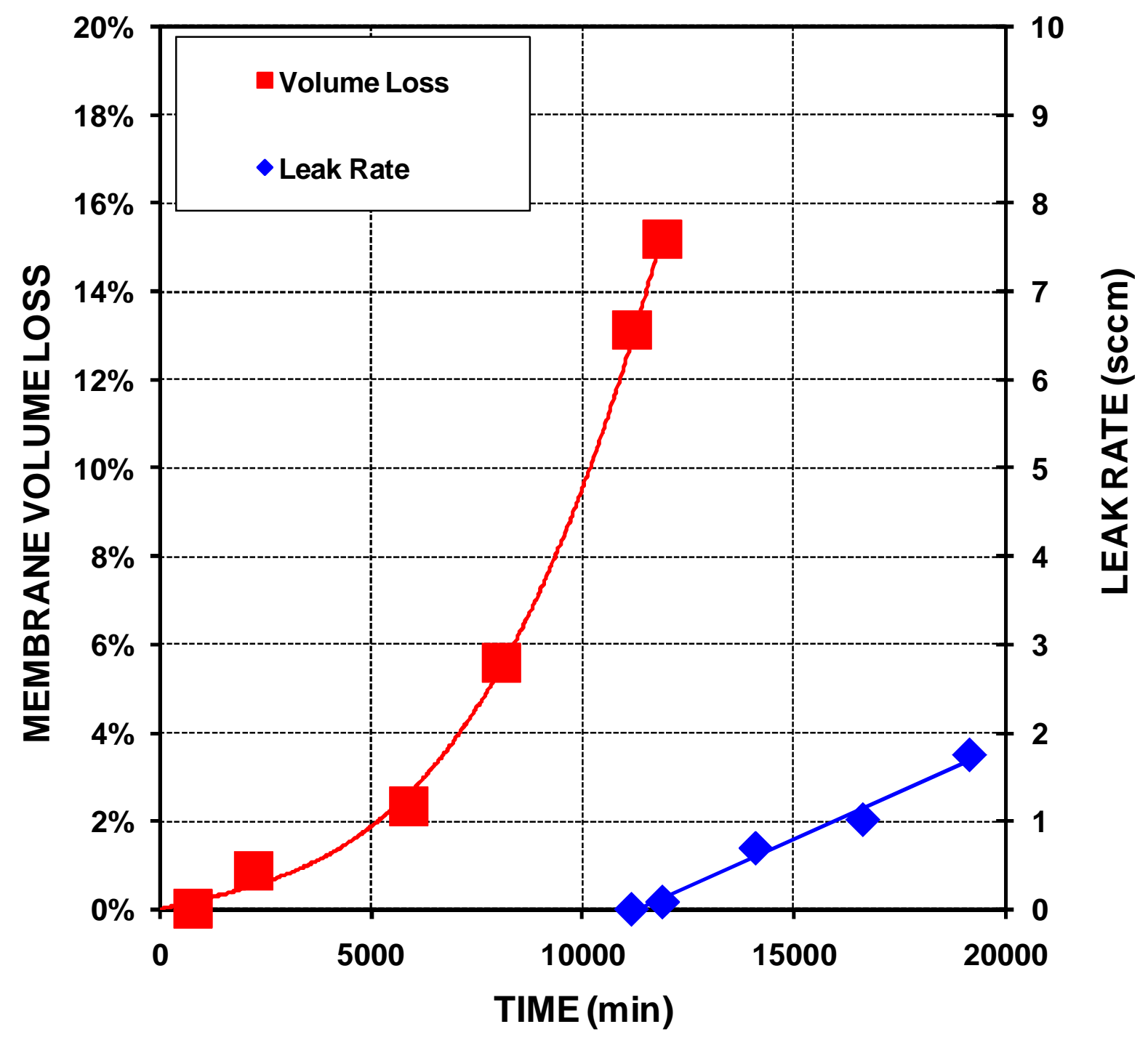




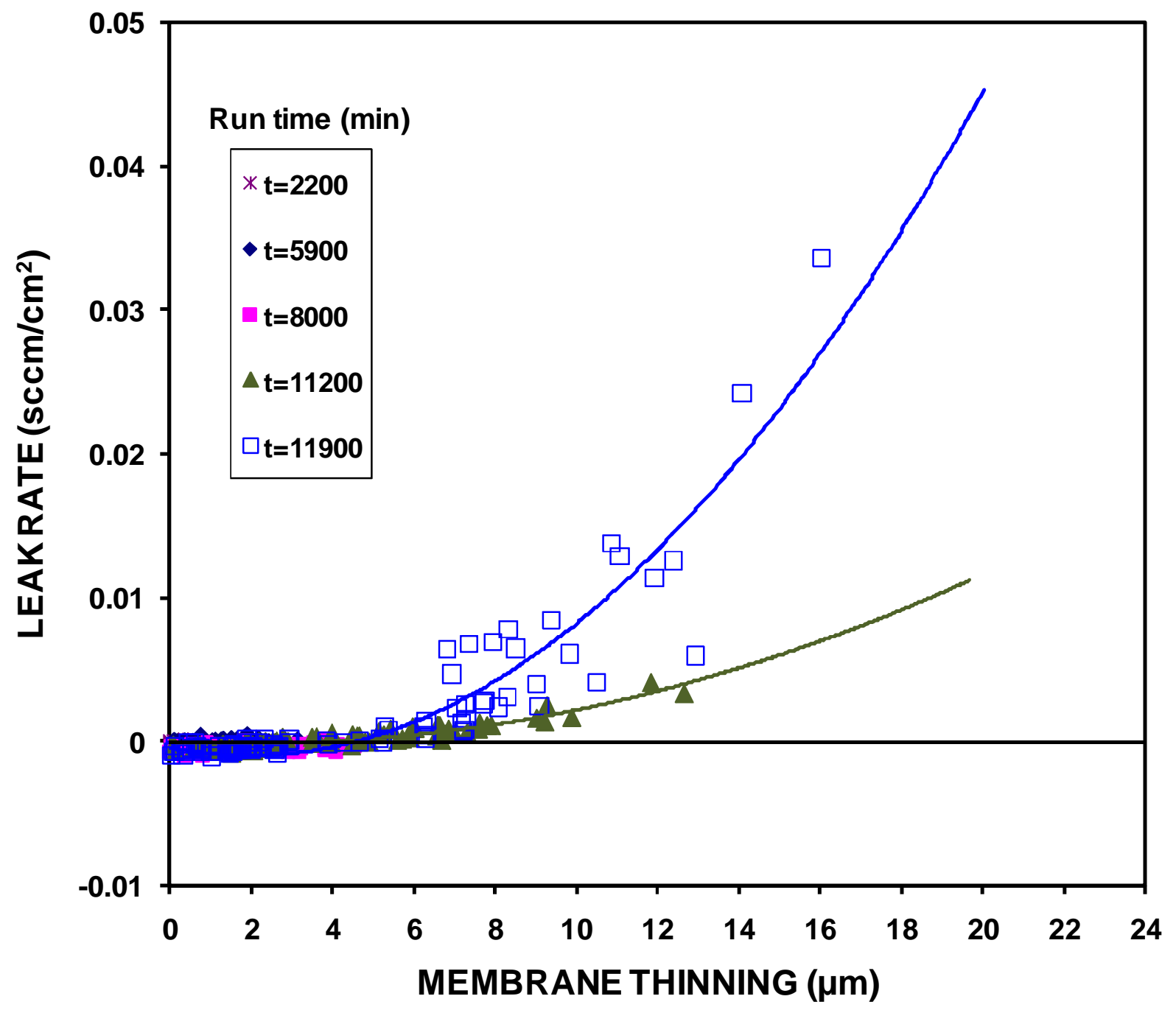

